\title{
Plasma Electrolytic Oxidation Ceramic Coatings on Zirconium (Zr) and ZrAlloys: Part I-Growth Mechanisms, Microstructure, and Chemical Composition
}

\author{
Navid Attarzadeh ${ }^{1,2}$ (D) and Chintalapalle V. Ramana $1,3, *$ (D) \\ 1 Center for Advanced Materials Research, University of Texas at El Paso, 500 W. Univ. Ave., \\ El Paso, TX 79968, USA; nattarzadeh@utep.edu \\ 2 Environmental Science and Engineering, University of Texas at El Paso, 500 W. Univ. Ave., \\ El Paso, TX 79968, USA \\ 3 Department of Mechanical Engineering, University of Texas at El Paso, 500 W. Univ. Ave., \\ El Paso, TX 79968, USA \\ * Correspondence: rvchintalapalle@utep.edu
}

Citation: Attarzadeh, N.; Ramana, C.V. Plasma Electrolytic Oxidation Ceramic Coatings on Zirconium (Zr) and ZrAlloys: Part I-Growth Mechanisms, Microstructure, and Chemical Composition. Coatings 2021, 11, 634. https://doi.org/10.3390/ coatings11060634

Academic Editor: Małgorzata Norek

Received: 8 April 2021

Accepted: 18 May 2021

Published: 25 May 2021

Publisher's Note: MDPI stays neutral with regard to jurisdictional claims in published maps and institutional affiliations.

Copyright: (c) 2021 by the authors. Licensee MDPI, Basel, Switzerland. This article is an open access article distributed under the terms and conditions of the Creative Commons Attribution (CC BY) license (https:// creativecommons.org/licenses/by/ $4.0 /)$.

\begin{abstract}
Recently, a significant number of research projects have been directed towards designing and developing ceramic coatings for zirconium-based substrates due to their outstanding surface properties and utilization in modern technologies. The plasma electrolytic oxidation (PEO) coating is an environmentally friendly wet coating method that can be performed in a wide range of electrolytes. The surface characteristics of PEO coatings can be tailored by changing electrochemical parameters, electrolyte composition, and substrate alloying elements to adopt a conformal and adhesive PEO ceramic coating for the final demanding applications in chemical, electronics, and energy technologies. This review focuses on deriving a deeper fundamental understanding of the PEO growth mechanisms and the effect of process parameters on transient discharge behavior at breakdown, initiation, and growth of the oxide layer and incorporating species from the electrolyte. It highlights the fundamental microstructural properties associated with structural defects, phase transformation, and the role of additives.
\end{abstract}

Keywords: ceramic coatings; plasma electrolytic oxidation (PEO) coating; microstructure; growth mechanism; zirconium and zirconium-based alloys

\section{Introduction}

Zirconium $(\mathrm{Zr})$ and $\mathrm{Zr}$-based alloys and oxides find widespread applications in many of the current emerging technological applications. Specifically, these materials are notable in structural engineering, electronics, optoelectronics, magneto-electronics, electrochemical, and energy-related technologies. Zr is affiliated with Group IV of the periodic table and demonstrates similar chemical and metallurgical properties to titanium. Zr can be identified as a refractory (melting point higher than transition metals), reactive, and corrosionresistant metal. $\mathrm{Zr}$ and $\mathrm{Ti}$ are sister metals of unique contrast. $\mathrm{Zr}$ is ranked 19th in abundance among chemical elements existing in the Earth's top layer.

German chemist Martin H. Klaproth introduced zirconium in 1789. Its purification process using iodide crystals and producing a ductile metal was performed by Arkel and Boer from Eindhoven, Holland [1]. Several alloy production programs started in the early 1950. The development of zirconium arose from increasing demands for the nuclear industry. A combination of several appealing features, such as resistance to irradiation damage, good corrosion-oxidation resistance, transparency to thermal neutrons, and adequate mechanical properties, has given $\mathrm{Zr}$ and its alloys the most suitable structural materials in nuclear applications like cladding nuclear fuels. Moreover, its extensive applications in nuclear submarines and research on developing its applications in the 
chemical process industries have grown remarkably. Zirconium also has found promising medical applications, such as surgical tools and instruments and implants $[2,3]$.

Zirconium alloys can be categorized based on the two primary applications: nuclear and nonnuclear. Alloys for nuclear applications are named $\mathrm{Zr}-1 \mathrm{Sn}-1 \mathrm{Nb}, \mathrm{Zr}-2.5 \mathrm{Nb}, \mathrm{Zr}-1 \mathrm{Nb}$, Zircaloy-2, and Zircaloy-4. The nonnuclear grades are named Zr700, Zr702, Zr704, Zr705, Zr706, where their production proceeds with low alloying contents. Nuclear grades are virtually free of hafnium, making alloys stabilized against thermal neutrons [1]. Generally, alloying elements can be categorized into two groups of $\alpha$-stabilizers and $\beta$-stabilizers, where tin, aluminum, and oxygen promote the $\alpha$ phase transformation. The Zr-rich end of the binary phase diagram of the $\alpha$-stabilizer alloying elements demonstrates peritectoid reactions. Moreover, adding iron, nickel, chromium, niobium, molybdenum, and hydrogen stabilizes the $\beta$ phase and represented binary diagrams exhibit eutectoid or monotectoid reactions in the $\mathrm{Zr}$-rich end [3]. The $\alpha$ structure is a hexagonal close-packed lattice, and the $\beta$ phase exhibits a body-centered cubic lattice. Figure 1 displays both $\alpha$ and $\beta$ crystal structures along with their crystallographic information.

(a)

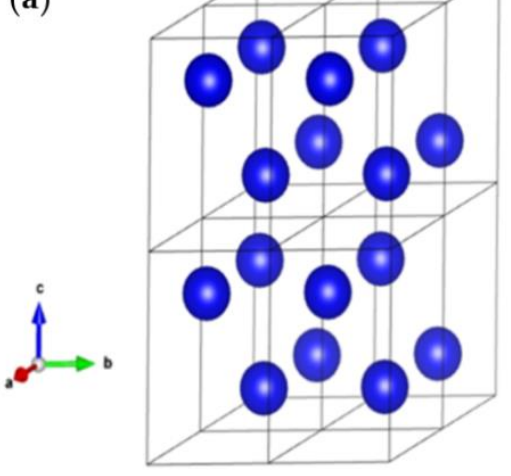

(b)

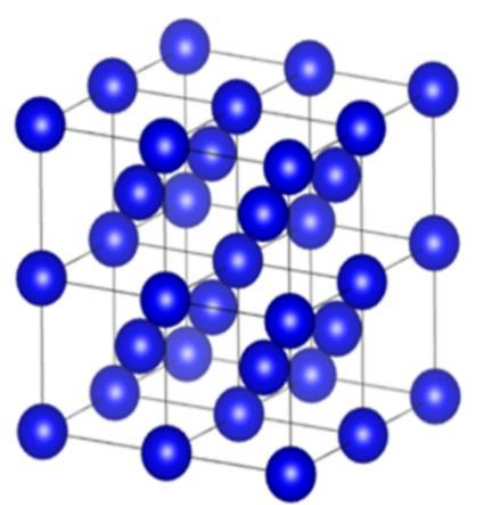

Figure 1. (a,b) crystal structures and crystallographic information of $\alpha$ and $\beta$ phases in $\mathrm{Zr}$ [4].

Zircaloy-2 and Zircaloy-4 nominally contain $1.5 \% \mathrm{Sn}$, while the latter contains more iron but no nickel to hamper hydrogen evolution. Both alloys are used in water-controlled reactors, such as pressurized boiling water reactors. The $\mathrm{Zr}-2.5 \mathrm{Nb}$ alloy is implemented in heavy-water-controlled reactors. From the nonnuclear category, Zr702 is commercially pure $\mathrm{Zr}$ and the most well-known alloy for corrosion protection applications. Zr705 is the strongest alloy with enhanced formability. Zr700 and Zr706, with trace oxygen content, are good choices for several forming applications, such as explosive cladding and deep drawing [2].

Generally, zirconium needs surface modification to be suitable for its major applications. For biomedical applications, modifications need to provide appropriate functional characteristics on the surface that facilitate precipitation of hydroxyapatite compounds and integrate the implant with the surrounding environment. Several surface treatments, such as sol-gel deposition [5] and plasma spray [6], have been used for the purpose above. However, these techniques suffer from either non-crystallite oxide films or weak adherence films demanding post-treatment to attain crystalline coating with outstanding adherence [7]. Moreover, these treatments typically evoke cracking, spallation of the film, or alteration in the features of the $\mathrm{Zr}$ substrate.

Among the studied methods, PEO demonstrates superior features compared to other methods owing to its simplicity of processing and uncomplicated production of a porous oxide film with significant adherence to the surface of $\mathrm{Zr}$ [8]. Both chemical and morphological modifications contribute to the single-step processing of PEO coatings to boost the applicability of zirconium. Moreover, the PEO method offers various merits compared to other techniques, including a low-cost process, the feasibility to grow crystalline surface materials owing to the high-temperature process suitable for phase transformation, and 
easy control over morphology and thickness of the produced oxide layers by changing the electrolyte composition and PEO processing parameters [9,10].

The PEO of $\mathrm{Zr}$ and its alloys has drawn much attention for the last 15 years, indicating the success and importance of this method in a multipurpose surface modification. Compared to light metals ( $\mathrm{Ti}, \mathrm{Al}$, and $\mathrm{Mg}$ ), there is a remarkable deficiency in detailed information about the nucleation and growth mechanism, microstructure, morphology, various phases and their transformation, and effects of process parameters on coatings properties that demand researchers to focus their studies in addressing them. From an application perspective, PEO studies can be categorized into two groups similar to alloy grades, namely nuclear power industry applications and biomedical applications.

This review aims to present the mechanism of oxide film formation and phase transformation in the PEO coating on $\mathrm{Zr}$ and its alloys. The microstructure and compositions of PEO coatings significantly influence the performance of a coating in different applications. We explain parameters' influence on the PEO coating and compare them for different applications. It should be noted that comprehensive identification of the growth mechanisms of the ceramic film using the PEO process on Zr-based substrates is currently not possible as the mechanisms are still obscure to some extent. Therefore, adopting models and theories already suggested for other valve metals like aluminum and magnesium requires us to fully discuss the discharge types and models after the breakdown voltage and finally to check the conformity of the reported surface morphology with the adopted mechanism.

\section{The Growth Mechanism of PEO Coating: The Influence of Process Parameters}

Generally, the PEO process on $\mathrm{Zr}$ is performed in either acidic or basic media. For the acidic media and galvanostatic conditions, it has been noted that the anodic films break down within the growing stage after the thickness of the oxide film has surpassed a critical value. This step is identified by the appearance of plasma discharges on the surface and a drop in the anodization rate $(\mathrm{d} E / \mathrm{d} t)$. Eventually, the voltage fluctuates once the oxide film's destruction/rebuilding process occurs [11]. Figure 2a illustrates the anodization plots of $\mathrm{Zr}$ acquired galvanostatically at $20 \mathrm{~mA} / \mathrm{cm}^{2}$ in phosphate electrolyte at $5{ }^{\circ} \mathrm{C}$. The anodization process can be divided into two recognizable steps: (I) the initial rise of the voltage $(V)$, (II) the voltage fluctuations due to rapid formation and breakdown of the $\mathrm{ZrO}_{2}$ film. The growth of the oxide film can be identified once the voltage rises linearly to reach the range of 300-350 V. At this step, ionic transport is the primary process controlling the film growth. A homogenous and compact film can be expected to grow on the $\mathrm{Zr}$ surface before the breakdown of the barrier layer [11]. While some slight deviation from linearity appears on the chronopotentiograph due to water oxidation on the oxide/electrolyte interface, voltage otherwise increases to the verge of a breakdown, where a distinct slope alteration occurs in the anodic graph. This event is identified by a series of simultaneous oscillations in anodization, crystallization of local oxide, and increasing internal lattice stress [12]. Once the voltage approaches the breakdown voltage $\left(V_{\mathrm{B}}\right)$, numerous micro sparks appear on the surface, indicating the beginning step of the PEO process. The chemical reactions occur between the participants of plasma and $\mathrm{Zr}$ electrodes in discharge channels [13]. The voltage fluctuations are related to the localized rupture/dissolving of the $\mathrm{ZrO}_{2}$ layer followed by the quick reformation of the oxide in the same origin. Ikonopisov et al. also showed that increasing the current density makes the anodization rate faster in the acidic electrolyte. Monitoring current density, anodization time, and electrolyte composition confirm the importance of these factors on altering discharge regimes. The electrolyte composition and current density affect the discharge density. Moreover, the anodization time and electrolyte composition influence the average area and discharge lifetimes [14]. As shown in Figure 2b, Sandhyarani et al. categorized the PEO process after the voltage breakdown into three states, including the dynamic sparking, the near steady-state (arcing), and the steady-state PEO, which is above the critical voltage $\left(V_{\mathrm{C}}\right)$ [13]. During the dynamic sparking of the PEO process, the voltage rises at a lower rate compared to early anodic oxidation of the $\mathrm{Zr}$ substrate because small, dense microdischarges are created with the 
contribution of ionic species and electrons to the current [15]. The creation of abundant micro sparks circulating over the whole surface is the primary characteristic of this step. During the near steady-state of the PEO process, the rate of increasing voltage generally declines to a lower value than the previous step on the order of one-tenth. At the second step, the intensity of microdischarges circulating quickly throughout the surface rises remarkably. At the final state, the voltage inclines to a steady-state trend concerning time, and no further rise seems to occur. This steady-state behavior can be explained by considering that most of the total current derives from the electric current related to the dielectric breakdown and the constant resistance of the film. Furthermore, at the final state, strong concentric and individual discharges with amplified size and prolonged periods are created on the surface. Thus, the surface suffers from the nonuniform distribution of discharges, meaning some regions remain discharge-free.


Figure 2. (a) Anodization curves of $\mathrm{Zr}$ at $5{ }^{\circ} \mathrm{C}$ obtained at $20 \mathrm{~mA} / \mathrm{cm}^{2}$ in $0.5 \mathrm{~mol} / \mathrm{L} \mathrm{H}_{3} \mathrm{PO}_{4}$ [11] (reproduced with permission number: 5034230474964, Elsevier); (b) chronopotentiograph for the PEO process at $0.150 \mathrm{~A} / \mathrm{cm}^{2}$ in $5 \mathrm{~g} / \mathrm{L} \mathrm{Na}_{3} \mathrm{PO}_{4} \cdot 12 \mathrm{H}_{2} \mathrm{O}$ electrolyte for $8 \mathrm{~min}$ [13] (reproduced with permission number: 5043471087024 , Elsevier); (c) schematic demonstration of the PEO process as a function of time.

The whole PEO process displaying the development of microdischarges as a function of time is illustrated schematically in Figure 2c, which represents the mechanism of oxide film formation during the PEO process. As shown in Figure 2c, the PEO process on $\mathrm{Zr}$ can be performed at potentials above $V_{\mathrm{B}}$. At these potentials, the remaining passive film 
cannot tolerate the strong electrical field and dielectric breakdown; therefore, it happens along with sparking over the metal surface $[9,12,14]$. Two phenomena are simultaneously involved in the PEO film growth on $\mathrm{Zr}$ : electrochemical reactions and plasma discharging processes over the metal/electrolyte interface [12]. In fact, plasma discharges are the main motive force for the growth of oxide layers, as they inject energy through numerous transient discharges that can melt the hitting surface, which is either metal or previously formed oxide film, and reconstruct the oxide film. Thus, fabrication of the PEO coating only demands a short treatment time to comprise a compact barrier layer and the components participating in the electrolyte. Unlike the direct current (DC) regime of the PEO process that the microdischarges are created only at the positive voltage side, the oxide film can form using both positive and negative waveform values under alternating current (AC) or pulsed bi-polar regime in excess of dielectric breakdown voltage. This condition promotes the formation of thick intermediate layers with a significant rise in hardness [16]. Arrabal et al. note that a thick intermediate layer can form during the PEO process using AC regime on $\mathrm{Mg}$ alloys after an abrupt decline in the voltage following the initial film growth at higher voltages [17]. Basically, the change in voltage after the initial step is associated with decreasing the intensity and appearance of the microdischarges, which are referred to as "soft sparking" [18]. Interestingly, the soft sparking phenomena were observed for the PEO process on Zr by Matykina et al. under AC regime and in the silicate electrolyte, where the voltage switched to reduced voltage after a treatment time of $18 \mathrm{~min}$ [19].

Chen et al. produced PEO coatings on Zircaloy-4 in silicate and pyrophosphate electrolyte separately and in their mixture for nuclear applications using an AC regime. They investigated the influence of the electrolyte composition on the coating features, including the microstructure and phase composition. It was noted that the steady-state voltage was the highest for the process in pyrophosphate electrolyte. In contrast, the process in silicate electrolyte showed the least [20]. Throughout the PEO process, microdischarges differ between aluminate, phosphate, and silicate electrolytes in terms of appearance and acoustic emission, and various coating compositions are stemmed from different microdischarge regimes and electrolyte composition.

The strong discharges initiating from the coating-substrate interface made the coating enriched in species derived from the substrate. In contrast, the near-surface discharges caused the participation of species from the electrolyte [20]. After the breakdown voltage, the initial microdischarges were short, plenty, and continuously disappearing and appearing at new locations for the process in silicate electrolyte. Therefore, the appearance of pancake-like features at the early stage of the PEO process could be attributed to forming of short-lived microdischarges and rapid solidification of molten materials in the discharge channels [20]. However, the solidification of molten materials to crystalline structure altered during the steady-state stage because fewer microdischarges were stronger and lasted longer at particular locations. Hussein et al. categorized discharge types originating from different regions during the PEO process primarily for the alloy of Al-Cu-Li [21-23]. We have suggested similar schematic representations for different types of discharges that might be created during the PEO process on $\mathrm{Zr}$ and its alloys. As shown in Figure 3a, discharges created during the PEO could be categorized into three types, including discharges initiating from the upper coating or gases and positioning over the coating surface (type A), discharges initiating from the substrate-coating interface (type $\mathrm{B})$, and discharges originating inside pores and cracks in the coating (type C). Therefore, type $\mathrm{A}$ and $\mathrm{C}$ could explain the gaseous discharging conditions adjacent to the surface and inside the pores of the coating. In contrast, the strong discharge of type $\mathrm{B}$ originated from the metal/oxide film interface. Hussein et al. believed that the electrolyte species could incorporate into the coating layer through type $\mathrm{A}$ and $\mathrm{C}$ discharges. In contrast, type $\mathrm{B}$ mainly caused participation of species from the substrate [21]. Figure $3 \mathrm{~b}$ illustrates the influence of type B discharges on the surface morphology of the PEO coating. Surface morphology and cross-section images are shown in Figure 3d,e to exemplify structural defects, pores, and cracks that may be created by type B discharges in the oxide film and adjacent 
to the coating/substrate interface. The appearance of type B discharges is associated with strong sparks. Moreover, this type of discharge promotes a pancake-like structure, which is common on the PEO coated surface of $\mathrm{Zr}$ alloys [20,24]. Later, a modified discharge model shown in Figure $3 \mathrm{c}$ introducing type $\mathrm{D}$ and $\mathrm{E}$ of discharges was suggested for $\mathrm{Zr}$ substrate based on the model for Al-Cu-Li alloys, suggested by Cheng et al. [24]. With a good conformability, the suggested model for the PEO coating on $\mathrm{Zr}$ in this review could explain the growth of the inner and outer layers. The internal pores adjacent to the inner layer/outer layer interface is the localized zone to receive the type D discharges. In contrast, the type E discharges strike the outer layer, creating large pores under pancake-like features, as shown in Figure 3c. Even though strong discharges of type D and E induced changes on the surface morphology, their impacts on the coating surface are less significant than that of the type B discharges. Therefore, this is the characteristic of microdischarges, either individually or collectively, that mainly dictates the phase formation, alteration of structures, and stress accumulation within oxide layers because of their main role in controlling the chemical and thermal conditions on the oxidizing surface. For this purpose, imaging techniques have been developed to study the microdischarge behavior during the PEO process. The spatial distribution, population density, size, and lifetime of the microdischarge could be recorded.

The application of optical emission spectroscopy (OES) to evaluate plasma discharges during the PEO process has recently drawn much attention among researchers. Cheng et al. captured the alteration of sparks' features during the PEO coating in the silicate electrolyte for $30 \mathrm{~min}$ [25]. They noted that the number of discharges reduced with treatment time, while their dimensions or intensities rose significantly. They attributed the reduction of the microdischarge number to the thickening effect of coatings, thus decreasing the number of weak sites. They finally categorized discharges during the PEO process based on their colors into three types. In the beginning, the discharges were white, small and numerous. In the second stage of the PEO process, between 3 and $10 \mathrm{~min}$, larger sparks with diameters of $\sim 0.28 \mathrm{~mm}$ appeared on the coating surface. In the last step of PEO (>10 $\mathrm{min})$, the large and long-lasting sparks turned orange in hue on the surface [25]. Later, in a separate study, Cheng et al. investigated the role of silicate and aluminate electrolytes on the PEO behavior of Zircaloy-2 [26]. Figure 4a displays the relation between the PEO coatings' thickness and treatment time in aluminate, silicate, and phosphate electrolytes [26,27].

Zhang et al. investigated forming the PEO coating in aluminate electrolytes. They introduced paths for the progress of reaction during the formation of zirconia $\left(\mathrm{ZrO}_{2}\right)$ and alumina $\left(\mathrm{Al}_{2} \mathrm{O}_{3}\right)$ phases [29]. In aluminate electrolyte, $\mathrm{AlO}_{2}^{-}$ions could react with water and thus forming either $\mathrm{Al}(\mathrm{OH})_{4}^{-}$or $\mathrm{Al}_{n}(\mathrm{OH})_{(4 n+2)}^{(n+2)-}$ [30]. These negatively charged ions could react with $\mathrm{Zr}^{4+}$ and form $\mathrm{ZrO}_{2}-\mathrm{Al}_{2} \mathrm{O}_{3}$ composite coatings. The order of reactions follows as [31,32]:

$$
\begin{gathered}
\mathrm{Zr} \rightarrow \mathrm{Zr}^{4+}+4 \mathrm{e}^{-} \\
\mathrm{Zr}^{4+}+2 \mathrm{OH}^{-}+2 \mathrm{H}_{2} \mathrm{O} \rightarrow \mathrm{ZrO}_{2}+2 \mathrm{H}_{3} \mathrm{O}^{+} \\
\mathrm{Zr}^{4+}+\mathrm{AlO}_{2}^{-}+2 \mathrm{H}_{2} \mathrm{O} \rightarrow \mathrm{ZrO}_{2}+2 \mathrm{Al}_{2} \mathrm{O}_{3} \\
\mathrm{Zr}^{4+}+\mathrm{Al}(\mathrm{OH})_{4}^{-} \rightarrow \mathrm{ZrO}_{2}+\mathrm{Al}_{2} \mathrm{O}_{3}+2 \mathrm{Al}(\mathrm{OH})_{3}+5 \mathrm{H}_{2} \mathrm{O} \\
4 \mathrm{Al}(\mathrm{OH})_{4}^{-} \rightarrow 2 \mathrm{Al}_{2} \mathrm{O}_{3}+2 \mathrm{OH}^{-}+3 \mathrm{H}_{2} \mathrm{O}
\end{gathered}
$$

After applying the voltage, a gas, mainly oxygen, evolved on the surface of the zirconium, thereby forming a thin layer of $\mathrm{ZrO}_{2}$ on the substrate using reactions (1) and (2). After passing the breakdown voltage (i.e., $400 \mathrm{~V}$ ), the oxide film broke, and many plasma discharges formed over the anode surface. Concurrently, $\mathrm{Zr}^{4+}$ metal cations diffused from the zirconium surface to the coating-electrolyte interface [31,32]. Zhang et al. deduced that the formation of $\mathrm{Al}_{2} \mathrm{O}_{3}-\mathrm{ZrO}_{2}$ composite coatings was due to significant migration of $\mathrm{AlO}_{2}^{-}$ and $\mathrm{Al}(\mathrm{OH})_{4}^{-}$toward the anode in the prolonged $\mathrm{PEO}$ procedure under the electric field, and then deposition on the earlier formed layer [29]. 

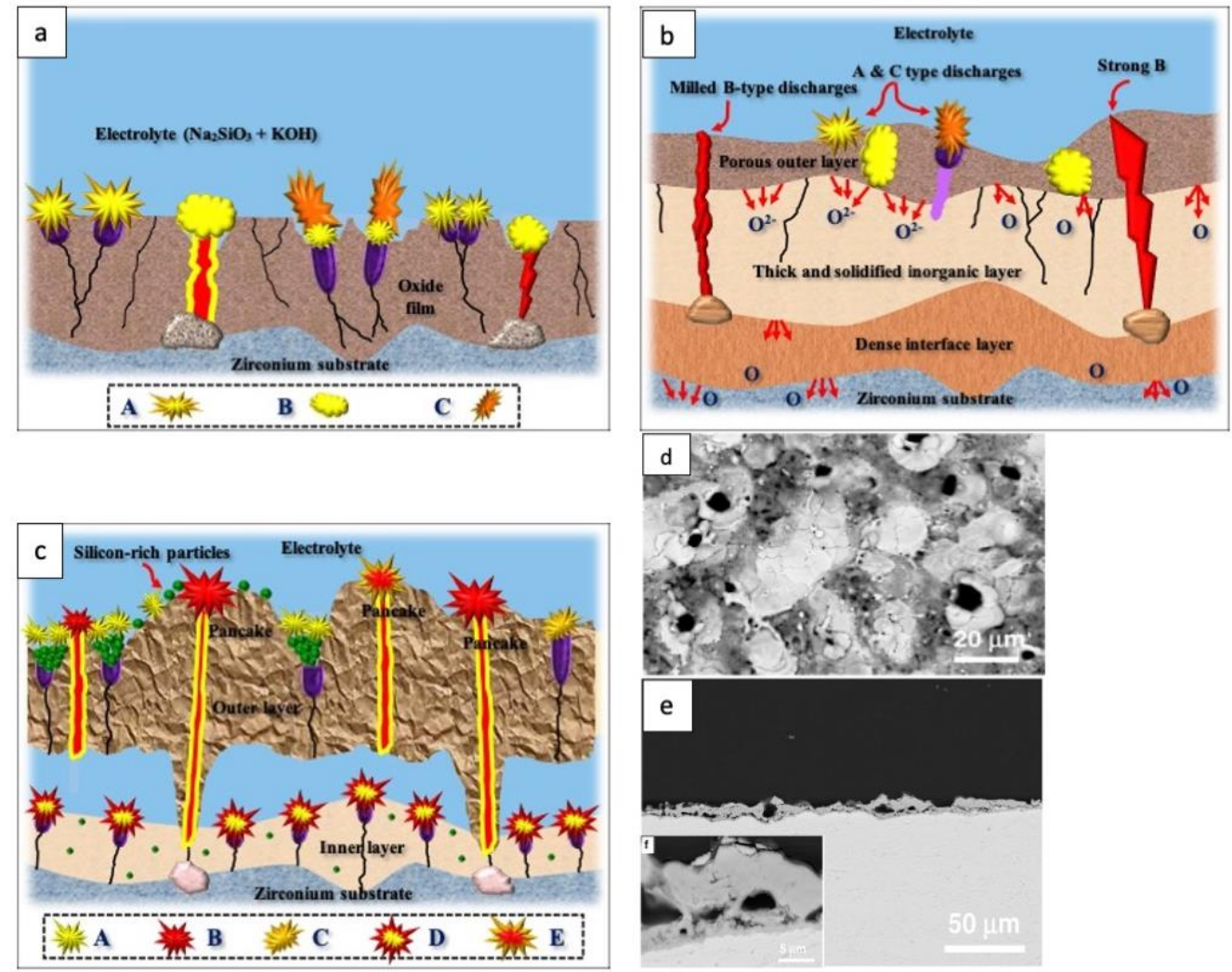

Figure 3. (a) Schematic illustration of the discharge types for the PEO coating on Zr in the silicate electrolyte based on the model suggested by Hussein et al. [21-23]; (b) Schematic representation of the discharge types for the PEO coating on $\mathrm{Zr}$ in the silicate electrolyte based on the model suggested by Cheng et al. [24]; (c) Effect of type B discharges on the surface morphology of the PEO coating on Zr substrate; (d,e) BS-SEM and cross-section image of the surface and the cross-section the PEO coating on Zircaloy-4 for $5 \mathrm{~min}$ at $100 \mathrm{~Hz}$; (f) Magnified cross-section image from the coating shown in image (e) [28] (reproduced with permission number: 5043471384823, Elsevier).

It was noted that during the outward/inward growth mechanism of PEO coating, the inward growth had an important role in the entire growth of the oxide layer [34,35], indicating that the fresh layer close to the substrate was the result of inward growth. The outward coating was predominantly "annealed" in the electrolyte. This was why the aluminum in the depth of $\mathrm{PEO}$ coating was amorphous, but the region close to the surface contained the crystalized form of $\mathrm{Al}_{2} \mathrm{O}_{3}$. The "annealing" process induced abnormal growth of nanoplate-like $\alpha-\mathrm{Al}_{2} \mathrm{O}_{3}$, while their deep growth was limited [29].

The appearance of discharges was recorded at various stages of the PEO treatment in both electrolytes. As shown in Figure 4d, the evolution of sparks' regime with time in the silicate electrolyte was similar to previous studies. However, this evolution did not behave similarly in the aluminate electrolyte after completing the early stage of the PEO process (600 s), shown in Figure 4e. After completing the PEO process, a striking contrast could be noticed between the surface morphologies of the two coatings from silicate and aluminate electrolytes. A uniform coating with a light appearance formed in silicate electrolyte throughout the whole treatment. However, the coating produced in aluminate electrolyte suffered blistering and spallation across the surface. The growth kinetics for these two coatings differed distinctively. A gradually accelerating rate of growth was recorded for coating formed in silicate electrolyte. In contrast, the growth rate in aluminate electrolytes was greater in the early coating stage (600 s). The rate then declined abruptly. The dissolution behavior of zirconium during the PEO in aluminate electrolyte could be divided into two regimes. First, during the pre-spallation stage of coating growth, the substrate initially underwent a relatively slow dissolution rate. After this, the dissolution 
rate switched to a much faster rate following the coating breakdown [26]. Sandhyarani et al. formed the PEO coating in electrolytes containing silicate, aluminate, and potassium hydroxide [36]. They reported that the electrolyte composition profoundly influenced the PEO voltage responses, such as the breakdown $\left(V_{\mathrm{B}}\right)$ and final voltage $\left(V_{\mathrm{f}}\right)$. Both $V_{\mathrm{B}}$ and $V_{\mathrm{f}}$ were higher in silicate electrolytes and decreased with $\mathrm{KOH}$ addition. Lu et al. also studied the effect of adding $\mathrm{KOH}$ and changing the duty cycle on the PEO process [37]. Adding $\mathrm{KOH}$ caused an abrupt drop in breakdown voltage from 500 to $264 \mathrm{~V}$ due to greater conductivity of electrolyte; however, they did not report the influence of duty cycle on alteration of the PEO process [37].


(e)


(f)
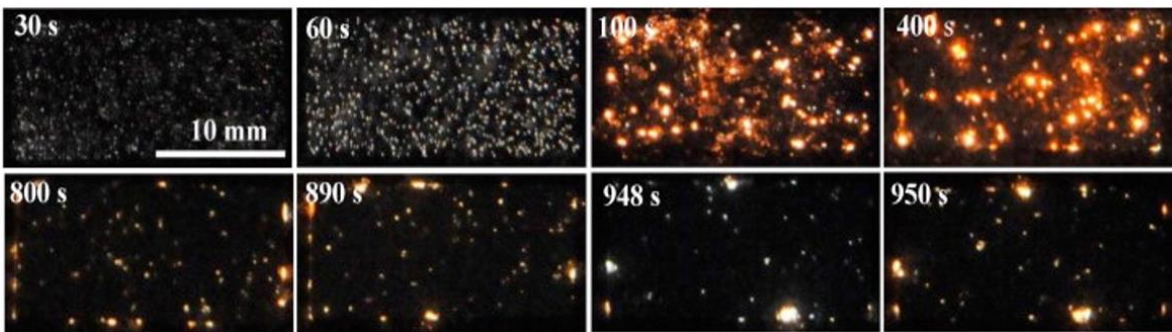

Figure 4. (a) Dependence of coating thickness on time of PEO on Zircaloy-2 in silicate and aluminate electrolytes and concentrations [26]; (b) Dependence of coating thickness on time of PEO on Zircaloy in different concentrations of aluminate electrolyte [27] (reproduced with permission number: 5043480179625 and 5043510569542, Elsevier); (c) and (d) Chronopotentiograph for the PEO process on Zirlo alloy in aluminate electrolyte with different concentration for pulse bipolar and pulse unipolar regimes, respectively [33] (reproduced with permission number: 5043511188587, Elsevier); (e) and (f) discharge appearances at different times of PEO in the silicate and aluminate electrolytes, respectively [26] (reproduced with permission number: 5043480179625, Elsevier). 
Cheng et al. comprehensively studied the role of negative pulse and PEO coating formation mechanism on Zirlo alloy in aluminate electrolyte with different concentrations [33]. The plasma discharge regime influenced the PEO process extensively. As mentioned earlier, the discharge develops from fine sparks at the initial stage. It then shifts to stronger and more intensive sparks with less population during the steady-state step of oxide film thickening. Recently, a particular type of plasma discharges termed "soft sparking" have been identified in some PEO processes of valve metals [27,38-40]. Authors particularly examined the anion deposition process under different $\mathrm{PEO}$ conditions and associated alteration of the plasma discharge regime. Figure $4 b, c$ demonstrated the chronopotentiograph under the bipolar and unipolar regimes, respectively [33]. It was evident that the breakdown voltage $\left(V_{\mathrm{B}}\right)$ dropped with aluminate concentration in electrolytes. This behavior could be attributed to the increased conductivity of the electrolyte, which could affect the overall cell potential $[33,41]$.

\section{Tailoring the Surface Morphology and Phase Composition of the PEO Coating}

The morphology of the PEO coating is under the influence of electrolyte composition. Alteration of coatings' characteristics, such as compactness and the number of pores and cracks on the surface of coatings, can be justified in light of the electrical conductivity directly affected by the electrolyte composition.

The PEO coating by Yan and Han in 2007 was one of the earliest studies using a pure $\mathrm{Zr}$ disc and an aqueous solution containing calcium acetate monohydrate and $\beta$ glycerophosphate disodium salt pentahydrate $\left(\beta-\mathrm{GPNa}_{2}\right)$ in a dilute concentration [42]. Two years later, they used an alkaline electrolyte of $\alpha-\mathrm{GPNa}_{2}$ and glycerin to produce a PEO coating with greater biocompatibility. Simka and his coworkers investigated the influence of electrolyte concentration on the composition of the PEO coating. They reported a direct relationship between the concentration of the potassium silicate in the electrolyte and the silicon content of the $\mathrm{PEO}$ coating, where the $\mathrm{Zr} / \mathrm{Si}$ atomic ratio decreased with increasing $\mathrm{K}_{2} \mathrm{SiO}_{3}$ concentration in the electrolyte [43]. Generally, treatment time directly influenced the PEO coatings' thickness. Increasing the thickness from 20 to $30 \mu \mathrm{m}$ was reported for the $\mathrm{PEO}$ process on the pure $\mathrm{Zr}$ substrate once the oxidation time prolonged from 5 to $20 \mathrm{~min}$ [44].

The crystalline $\mathrm{ZrO}_{2}$ contains three phases known as polymorphs under atmospheric pressure, as shown in Figure 5a-c. They are monoclinic (stable at temperatures below $1000{ }^{\circ} \mathrm{C}$ ), tetragonal (stable at temperatures between 1000 and $1500^{\circ} \mathrm{C}$ ), and cubic (stable at temperatures above $1500{ }^{\circ} \mathrm{C}$ ), where $\mathrm{m}-\mathrm{ZrO}_{2}$ is the most stable phase at the room temperature, and the other phases are stable at high-temperature [15]. Having said that, under equilibrium conditions, it has been seen that liquid $\mathrm{ZrO}_{2}$ transforms to $\mathrm{c}-\mathrm{ZrO}_{2}$ at $2680{ }^{\circ} \mathrm{C}$, then $t-\mathrm{ZrO}{ }_{2}$ appears at $2370{ }^{\circ} \mathrm{C}$, and eventually, transformation ends up to $\mathrm{m}-\mathrm{ZrO}_{2}$ at $1240{ }^{\circ} \mathrm{C}$ [45]. For a short period of $10^{-3}-10^{-4} \mathrm{~s}$, the local temperature rises to $10^{4} \mathrm{~K}$ once the plasma forms on the surface [46]. Thus, the metallic $\mathrm{Zr}$ and its alloys transform to molten phase instantaneously under such high temperatures and solidify very quickly under non-equilibrium conditions. Therefore, this results in forming a mixture of monoclinic and tetragonal phases. The ratio of phases depends on how fast transformation occurs. The phase composition depends on several factors, including the electrolyte composition, the formation voltage, the surface pretreatment, the process treatment time, the alloying elements of the zirconium substrate, and additives participating in the PEO coating [20]. The coating properties are strongly influenced by the ratio of the zirconia phases present in the coating.

Similarly, a transition from tetragonal to monoclinic was reported for galvanostatic oxidation treatment. Accordingly, an impromptu phase transition occurs after the electrolyte breakdown process under the constant charge of $3.2 \mathrm{C} / \mathrm{cm}^{2}$. At the initiation of the breakdown stage, both tetragonal and monoclinic phases coexist. The transition between the tetragonal and monoclinic phases happens because of the high strain energy related to the difference in the molar volume between the two phases [11]. The coexistence of 
both phases before an electrolytic breakdown can be explained in terms of the high field strength and the local energy created by the PEO process, confirmed by the intense spark generation. After the electrolytic breakdown in the galvanostatic regime of anodization, a continuous phase transformation proceeds from the semi-stable tetragonal phase to the stable monoclinic phase termed as a martensitic transformation.

Table 1 represents works performed by many researchers on the PEO coatings using various electrolytes and processing parameters.

Table 1. PEO process on $\mathrm{Zr}$ and $\mathrm{Zr}$ alloys representing different processing parameters.

\begin{tabular}{|c|c|c|c|c|c|c|c|c|}
\hline \multirow[b]{2}{*}{ Substrates } & \multirow[b]{2}{*}{ Electrolytes } & \multicolumn{4}{|c|}{ PEO Processes Conditions } & \multirow[b]{2}{*}{ Coating Composition } & \multirow[b]{2}{*}{$\begin{array}{l}\text { Coating } \\
\text { Features }\end{array}$} & \multirow[b]{2}{*}{ Ref } \\
\hline & & $\begin{array}{l}\text { Pulse } \\
\text { Fre. (Hz) }\end{array}$ & $\begin{array}{l}\text { Duty } \\
\text { Cycle }\end{array}$ & Time (min) & $\begin{array}{l}\text { App. Voltage or } \\
\text { Current }\end{array}$ & & & \\
\hline Pure Zr & $\begin{array}{c}0.2 \mathrm{M} \mathrm{Ca}\left(\mathrm{CH}_{3} \mathrm{CO}_{2}\right)_{2} \cdot \mathrm{H}_{2} \mathrm{O} \\
0.02 \mathrm{M} \beta-\mathrm{CPNa}_{2}\end{array}$ & 100 & 30 & 5 & $350-500 \mathrm{~V}$ & $\begin{array}{c}\mathrm{Ca}_{0.15} \mathrm{Zr}_{0.85} \mathrm{O}_{1.85} \text { (Ca-PSZ) } \\
\mathrm{m}-\mathrm{ZrO}_{2}\end{array}$ & BS: $57.4 \pm 2.1$ & [42] \\
\hline Pure Zr & $\begin{array}{c}0.15 \alpha-\mathrm{GPNa}_{2} \\
0.1 \mathrm{NaOH}, 5 \mathrm{M} \text { Glycerin }\end{array}$ & 100 & 26 & 5 & $400 \mathrm{~V}$ & $\begin{array}{l}\mathrm{m}-\mathrm{ZrO}_{2} \text { (major) } \\
t-\mathrm{ZrO}_{2} \text { (minor) }\end{array}$ & Th.: 7 & [47] \\
\hline Pure Zr & $\mathrm{K}_{2} \mathrm{SiO}_{3}, 5 \mathrm{~g} / \mathrm{dm}^{3} \mathrm{KOH}$ & - & - & 5 & $100,200,400 \mathrm{~V}$ & $\mathrm{SiO}_{2}, \mathrm{Zr}_{2} \mathrm{SiO}_{3}, \mathrm{ZrO}_{2}$ & Th: 5 to 72 & [43] \\
\hline Pure Zr & $0.05 \mathrm{M}\left(\mathrm{H}_{3} \mathrm{PO}_{4}\right.$ or $\left.\mathrm{H}_{2} \mathrm{C}_{2} \mathrm{O}_{4}\right)$ & Cons. & - & 1 to 10 & 10 or $20 \mathrm{~mA} / \mathrm{cm}^{2}$ & $\mathrm{~m}-\mathrm{ZrO}_{2}$ and $t-\mathrm{ZrO}_{2}$ & - & - \\
\hline Pure Zr & 0.05 and $0.1 \mathrm{M}\left(\mathrm{H}_{3} \mathrm{PO}_{4}\right.$ or $\left.\mathrm{H}_{2} \mathrm{C}_{2} \mathrm{O}_{4}\right)$ & Cons. & - & Varies & $3.2-43.2 \mathrm{C} / \mathrm{cm}^{2}$ & $\mathrm{~m}-\mathrm{ZrO}_{2}$ and $t-\mathrm{ZrO}_{2}$ & - & [11] \\
\hline Pure Zr & $0.2-0.35 \mathrm{M} \mathrm{Na}_{2} \mathrm{AlO}_{2}$ & 100 & 26 & 30 & $400 \mathrm{~V}$ & $\alpha-\mathrm{Al}_{2} \mathrm{O}_{3}, t-\mathrm{ZrO}{ }_{2}$, and $\mathrm{m}-\mathrm{ZrO}_{2}$ & BS: $30-52$ & [48] \\
\hline Pure Zr & $5 \mathrm{~g} / \mathrm{L} \mathrm{Na}_{3} \mathrm{PO}_{4} \cdot 12 \mathrm{H}_{2} \mathrm{O}$ (TSOP) & 50 & 95 & $2,4,6,8$ & $150 \mathrm{~mA} / \mathrm{cm}^{2}$ & $\begin{array}{c}t-\mathrm{ZrO}_{2}(1-7 \mathrm{vol} \%) \\
\mathrm{m}-\mathrm{ZrO}_{2}(99-93 \mathrm{vol} \%)\end{array}$ & Th: $3-17$ & [13] \\
\hline Pure Zr & $12 \mathrm{~g} / \mathrm{L} \mathrm{Na}_{2} \mathrm{SiO}_{3}, 2 \mathrm{~g} / \mathrm{L} \mathrm{KOH}$ & 50 & - & $5-120$ & $\begin{array}{c}480(+), 120(-) \mathrm{V} \\
0.25 \mathrm{~A} / \mathrm{cm}^{2}\end{array}$ & $\mathrm{~m}-\mathrm{ZrO}_{2}$ and $t-\mathrm{ZrO}_{2}$ & Th: $4.1-167$ & [45] \\
\hline Zirlo $^{\mathrm{TM}}$ & $30 \mathrm{~g} / \mathrm{L} \mathrm{Na}_{2} \mathrm{SiO}_{3} \cdot 5 \mathrm{H}_{2} \mathrm{O}$ and $2.8 \mathrm{~g} / \mathrm{L} \mathrm{KOH}$ & 50 & - & $19 \mathrm{~s}, 30,60$ & $10 \mathrm{~A} / \mathrm{dm}^{2} 150 \mathrm{~V}$ & $\mathrm{c}-\mathrm{ZrO}_{2}, \mathrm{~m}-\mathrm{ZrO}_{2} t-\mathrm{ZrO}_{2}$ & - & [19] \\
\hline Zircaloy-4 & $\begin{array}{c}30 \mathrm{~g} / \mathrm{L} \mathrm{Na} \mathrm{SiO}_{3} \cdot 5 \mathrm{H}_{2} \mathrm{O}+4.88 \mathrm{~g} / \mathrm{L} \mathrm{KOH} 10 \mathrm{~g} / \mathrm{L} \\
\mathrm{Na}_{4} \mathrm{P}_{2} \mathrm{O}_{7} \cdot 10 \mathrm{H}_{2} \mathrm{O} 10 \mathrm{~g} / \mathrm{L}\left(\mathrm{Na}_{2} \mathrm{SiO}_{3} \cdot 5 \mathrm{H}_{2} \mathrm{O}+\right. \\
\left.\mathrm{Na}_{4} \mathrm{P}_{2} \mathrm{O}_{7} \cdot 10 \mathrm{H}_{2} \mathrm{O}\right)\end{array}$ & 50 & 30 & 30 & $300 \mathrm{~mA} / \mathrm{cm}^{2}$ & $\mathrm{~m}-\mathrm{ZrO}_{2}$ and $t-\mathrm{ZrO}_{2}$ or only $\mathrm{m}-\mathrm{ZrO}_{2}$ & - & [20] \\
\hline Zircaloy-4 & $30 \mathrm{~g} / \mathrm{L} \mathrm{Na}_{2} \mathrm{SiO}_{3} \cdot 5 \mathrm{H}_{2} \mathrm{O}+4.88 \mathrm{~g} / \mathrm{L} \mathrm{KOH}$ & 100 & 30 & 30 & $300 \mathrm{~mA} / \mathrm{cm}^{2}$ & $\mathrm{~m}-\mathrm{ZrO}_{2}$ and $t-\mathrm{ZrO}_{2}$ & Th: 15 & [28] \\
\hline Zircaloy-2 & $8 \mathrm{~g} / \mathrm{L} \mathrm{Na}_{2} \mathrm{SiO}_{3} \cdot 9 \mathrm{H}_{2} \mathrm{O}+1 \mathrm{~g} / \mathrm{L} \mathrm{KOH}$ & 1000 & 20 & $15 \mathrm{~s}$ to $30 \mathrm{~min}$ & $\begin{array}{l}400 \mathrm{~mA} / \mathrm{cm}^{2}(+) \\
300 \mathrm{~mA} / \mathrm{cm}^{2}(-)\end{array}$ & $\mathrm{m}-\mathrm{ZrO}_{2}$ and $t-\mathrm{ZrO}_{2}$ & - & [25] \\
\hline Zircaloy-2 & $\begin{array}{c}8 \mathrm{~g} / \mathrm{L} \mathrm{Na}_{2} \mathrm{SiO}_{3} \cdot 9 \mathrm{H}_{2} \mathrm{O}+1 \mathrm{~g} / \mathrm{L} \mathrm{KOH} \\
6 \mathrm{~g} / \mathrm{LNAAlO}_{2}+8 \mathrm{~g} / \mathrm{L} \mathrm{Na} \mathrm{Na}_{2} \mathrm{O}_{7} \cdot 10 \mathrm{H}_{2} \mathrm{O}+ \\
5 \mathrm{~g} / \mathrm{L} \mathrm{KOH}\end{array}$ & 1000 & 20 & 30 & $\begin{array}{l}150(+) \mathrm{mA} / \mathrm{cm}^{2} \\
100(-) \mathrm{mA} / \mathrm{cm}^{2}\end{array}$ & $\mathrm{~m}-\mathrm{ZrO}_{2}$ and $t-\mathrm{ZrO}_{2}$ & - & [49] \\
\hline Pure Zr & $\begin{array}{c}13 \mathrm{~g} / \mathrm{L}\left(\mathrm{Na}_{3} \mathrm{PO}_{4} \cdot 12 \mathrm{H}_{2} \mathrm{O}\right) \\
10 \mathrm{~g} / \mathrm{L}\left(\mathrm{Na}_{3} \mathrm{PO}_{4} \cdot 12 \mathrm{H}_{2} \mathrm{O}\right)+3 \mathrm{~g} / \mathrm{L} \mathrm{KOH} \\
13 \mathrm{~g} / \mathrm{L}\left(\mathrm{Na}_{2} \mathrm{SiO}_{3} \cdot 9 \mathrm{H}_{2} \mathrm{O}\right) \\
10 \mathrm{~g} / \mathrm{L}\left(\mathrm{Na}_{2} \mathrm{SOO}_{3} \cdot 9 \mathrm{H}_{2} \mathrm{O}\right)+3 \mathrm{~g} / \mathrm{LOH} \\
5 \mathrm{~g} / \mathrm{L}\left(\mathrm{Na}_{3} \mathrm{PO}_{4} \cdot 12 \mathrm{H}_{2} \mathrm{O}+\mathrm{Na}_{2} \mathrm{SiO}_{3} \cdot 9 \mathrm{H}_{2} \mathrm{O}\right)+ \\
3 \mathrm{~g} / \mathrm{L} \mathrm{KOH} \\
\end{array}$ & 50 & 95 & 6 & $150 \mathrm{~mA} / \mathrm{cm}^{2}$ & $\begin{array}{l}\mathrm{m}-\mathrm{ZrO}_{2}(94), t-\mathrm{ZrO}_{2}(6) \mathrm{Vol} \% \\
\mathrm{~m}-\mathrm{ZrO}_{2}(94), t-\mathrm{ZrO}_{2}(6) \mathrm{Vol} \% \\
\mathrm{~m}-\mathrm{ZrO}_{2}(91), t-\mathrm{ZrO}_{2}(9) \mathrm{Vol} \% \\
\mathrm{~m}-\mathrm{ZrO}_{2}(91), t-\mathrm{ZrO}_{2}(9) \mathrm{Vol} \% \\
\mathrm{~m}-\mathrm{ZrO}_{2}(95), t-\mathrm{ZrO}_{2} \text { (5) } \mathrm{Vol} \%\end{array}$ & $\begin{array}{c}\text { Th: } 95 \pm 0.7 \\
\text { Th: } 6.3 \pm 0.4 \\
\text { Th: } 7 \pm 1.1 \\
\text { Th: } 5.7 \pm 0.9 \\
\text { Th: } 6.9 \pm 0.8\end{array}$ & [36] \\
\hline Zircaloy-2 & 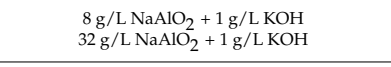 & 1000 & 20 & $\begin{array}{l}30 \text { (dil.) } \\
10 \text { (con.) }\end{array}$ & $\begin{array}{l}150 \mathrm{~mA} / \mathrm{cm}^{2}(+) \\
100 \mathrm{~mA} / \mathrm{cm}^{2}(-)\end{array}$ & $\gamma-\mathrm{Al}_{2} \mathrm{O}_{3}, \underset{t-\mathrm{ZrO}_{2}}{\text { amorphous } \mathrm{Al}_{2} \mathrm{O}_{3}}$ & $\begin{array}{l}\text { Th: } 78.5 \\
\text { Th: } 65.4\end{array}$ & [27] \\
\hline Zircaloy-2 & $12 \mathrm{~g} / \mathrm{L} \mathrm{Na}{ }_{2} \mathrm{SiO}_{3} \cdot 9 \mathrm{H}_{2} \mathrm{O}+15 \mathrm{~g} / \mathrm{L}\left(\mathrm{NaPO}_{3}\right)_{6}$ & 1000 & 8 & 20,60 & $\begin{array}{l}200 \mathrm{~mA} / \mathrm{cm}^{2}(+), \\
150 \mathrm{~mA} / \mathrm{cm}^{2}(-)\end{array}$ & - & Th: 60,122 & [50] \\
\hline Pure Zr & $0.3 \mathrm{M} \mathrm{NaAlO}_{2}$ and $0.03 \mathrm{M} \mathrm{Na}_{2} \mathrm{HPO}_{4}$ & 100 & 26 & $5,15,20,30$ & $400 \mathrm{~V}$ & Nanoplate-like $\alpha-\mathrm{Al}_{2} \mathrm{O}_{3}, \mathrm{~m}-\mathrm{ZrO}_{2}, t-\mathrm{ZrO}_{2}$ & - & [30] \\
\hline Pure Zr & $0.1 \mathrm{M} \mathrm{C}_{6} \mathrm{H}_{8} \mathrm{O}_{7}$ & - & - & $1,2,3,5,10$ & $100 \mathrm{~mA} / \mathrm{cm}^{2}$ & $\mathrm{~m}-\mathrm{ZrO}_{2}$ & - & [51] \\
\hline Pure Zr & $\begin{array}{c}30 \mathrm{~g} / \mathrm{L} \mathrm{Ca}\left(\mathrm{CH}_{3} \mathrm{COO}\right)_{2} \cdot \mathrm{H}_{2} \mathrm{O}, 8 \mathrm{~g} / \mathrm{L} \\
\mathrm{C}_{3} \mathrm{H}_{7} \mathrm{Na}_{2} \mathrm{O}_{6} \mathrm{P} \cdot \mathrm{H}_{2} \mathrm{O} \text { and } 2 \mathrm{~g} / \mathrm{L} \mathrm{KOH}\end{array}$ & 400 & - & 5 & $4 \mathrm{~A} / \mathrm{cm}^{2}$ & $\mathrm{HA}, \mathrm{Ca}-\mathrm{PSZ}, \mathrm{m}-\mathrm{ZrO}_{2}$ & - & [52] \\
\hline Zirlo alloy & $(2-56 \mathrm{~g} / \mathrm{L}) \mathrm{NaAlO}_{2}+1 \mathrm{~g} / \mathrm{L} \mathrm{KOH}$ & 1000 & 20 & $5,10,20$ & $\begin{array}{l}0.14(+) \mathrm{A} / \mathrm{cm}^{2} \\
0.05(-) \mathrm{A} / \mathrm{cm}^{2}\end{array}$ & $(\gamma, \alpha)-\mathrm{Al}_{2} \mathrm{O}_{3}, \mathrm{~m}-\mathrm{ZrO}_{2}$ and $t-\mathrm{ZrO}_{2}$ & - & [33] \\
\hline Pure Zr & $\begin{array}{c}15 \mathrm{~g} / \mathrm{L} \mathrm{NaSiO} \mathrm{Na}_{3}+2 \mathrm{~g} / \mathrm{L} \mathrm{NaOH}+ \\
0.025 \mathrm{M} \mathrm{AgC}_{2} \mathrm{H}_{3} \mathrm{O}_{2}\end{array}$ & - & - & 3 & $\begin{array}{l}400(+) \mathrm{V} \\
80(-) \mathrm{V}\end{array}$ & $\mathrm{ZrSiO}_{4}, \mathrm{~m}-\mathrm{ZrO}_{2}$ and $t-\mathrm{ZrO}_{2}$ & - & [53] \\
\hline Pure Zr & $0.1 \mathrm{M} \mathrm{K}_{3} \mathrm{PO}_{4}+(0.01,0.05,0.1) \mathrm{M} \mathrm{KOH}$ & 1000 & $25,75,100$ & - & $200 \mathrm{~mA} / \mathrm{cm}$ & (dominant) $\mathrm{m}-\mathrm{ZrO}_{2}$ & - & [37] \\
\hline Pure Zr & $0.25 \mathrm{M} \mathrm{Ca}\left(\mathrm{CH}_{3} \mathrm{CO}_{2}\right)_{2} \cdot \mathrm{H}_{2} \mathrm{O}+0.06 \mathrm{M} \beta-\mathrm{CaGP}$ & 50 & - & $5,10,15$ & $0.292 \mathrm{~A} / \mathrm{cm}^{2}$ & $\mathrm{c}-\mathrm{ZrO}_{2}, \mathrm{CaZrO}_{3}, \mathrm{HA}$ & - & [54] \\
\hline Pure Zr & $\begin{array}{c}\text { TSOP: } \mathrm{Na}_{3} \mathrm{PO}_{4} \cdot 12 \mathrm{H}_{2} \mathrm{O} \text { with }\left(\mathrm{Al}_{2} \mathrm{O}_{3}, \text { or } \mathrm{CeO}_{2}\right. \\
\left.\text { or } \mathrm{ZrO}_{2}\right)\end{array}$ & 50 & 90 & 6 & $150 \mathrm{~mA} / \mathrm{cm}^{2}$ & $\mathrm{~m}-\mathrm{ZrO}_{2}$ and $t-\mathrm{ZrO}_{2}$ & $5-7$ & [55] \\
\hline Pure Zr & $\mathrm{Ca}\left(\mathrm{CH}_{3} \mathrm{COO}\right)_{2} \cdot \mathrm{H}_{2} \mathrm{O}$ and $\mathrm{C}_{3} \mathrm{H}_{7} \mathrm{Na}_{2} \mathrm{O}_{6} \mathrm{P} \cdot 5 \mathrm{H}_{2} \mathrm{O}$ & - & - & $2.5-30$ & $172 \mathrm{~mA} / \mathrm{cm}^{2}$ & $t-\mathrm{ZrO}_{2}$ & - & [56] \\
\hline Pure Zr & $0.25 \mathrm{M} \mathrm{Ca}\left(\mathrm{CH}_{3} \mathrm{COO}\right)_{2} \cdot \mathrm{H}_{2} \mathrm{O}+0.06 \mathrm{M} \beta-\mathrm{CaGP}$ & - & - & 15 & $260 \mathrm{~mA} / \mathrm{cm}^{2}$ & $\mathrm{c}-\mathrm{ZrO}_{2}, \mathrm{CaZrO}_{3}, \mathrm{HA}$ & - & [57] \\
\hline \multirow[t]{2}{*}{ Zircaloy-4 } & $10 \mathrm{~g} / \mathrm{L} \mathrm{Na}_{2} \mathrm{SiO}_{3}+3 \mathrm{~g} / \mathrm{L} \mathrm{KOH}$ & \multirow[t]{2}{*}{600} & \multirow[t]{2}{*}{8} & \multirow[t]{2}{*}{20} & \multirow[t]{2}{*}{$550 \mathrm{~V}$} & \multirow{2}{*}{$\mathrm{m}-\mathrm{ZrO}_{2}$ and $t-\mathrm{ZrO}_{2}$} & 5 & \multirow[t]{2}{*}[58]{} \\
\hline & $10 \mathrm{~g} / \mathrm{L} \mathrm{Na}{ }_{3} \mathrm{PO}_{4}+3 \mathrm{~g} / \mathrm{L} \mathrm{KOH}$ & & & & & & 4 & \\
\hline Pure Zr & $\begin{array}{l}0.25 \mathrm{M} \text { calcium acetate } \\
0.06 \mathrm{M} \beta \text {-CaGP }\end{array}$ & - & - & 5 & $0.370 \mathrm{~A} / \mathrm{cm}^{2}$ & $\begin{array}{c}\mathrm{Ca}_{0.15} \mathrm{Zr}_{0.85} \mathrm{O}_{1.85} \\
\mathrm{c}-\mathrm{ZrO}_{2}, \mathrm{CaZrO}_{3}, \mathrm{Cu}_{2}\left(\mathrm{P}_{2} \mathrm{O}_{7}\right)\end{array}$ & $21.8 \pm 2.4$ & [59] \\
\hline $\begin{array}{l}\mathrm{Zr} \text { alloy }(\mathrm{Nb}, \\
\mathrm{Sn})\end{array}$ & $\begin{array}{l}15 \mathrm{~g} / \mathrm{L} \mathrm{Na}{ }_{2} \mathrm{SiO}_{3}+3 \mathrm{~g} / \mathrm{L} \mathrm{NaF}+15 \mathrm{~g} / \mathrm{L} \mathrm{KOH} \\
\text { with } 0.1 \mathrm{~g} / \mathrm{L}\left(\mathrm{Al}_{2} \mathrm{O}_{3}, \mathrm{MoS}_{2}, \mathrm{CeO}_{2} \text {, and GO) }\right.\end{array}$ & 300 & 30 & 15 & $260 \mathrm{~V}$ & $\mathrm{~m}-\mathrm{ZrO}_{2}$ and $t-\mathrm{ZrO}_{2}$ & - & [60] \\
\hline
\end{tabular}

(Th: Thickness vs. $\mu \mathrm{m})$, (BS: Bond Strength vs. MPa). 
The volume fraction of $t-\mathrm{ZrO}_{2}$ and $\mathrm{m}-\mathrm{ZrO}_{2}$ can be estimated from the XRD pattern using the empirical equation suggested by Weimin et al. [61], as follows:

$$
\begin{gathered}
X_{\mathrm{m}}=\frac{I_{\mathrm{m}}(111)+I_{\mathrm{m}}(\overline{111})}{I_{\mathrm{m}}(111)+I_{\mathrm{m}}(\overline{1} 11)+I_{\mathrm{t}}(111)} \times 100 \% \\
V_{\mathrm{m}}=\frac{1.311 X_{\mathrm{m}}}{1+0.311 X_{\mathrm{m}}} \\
V_{\mathrm{t}}=1-V_{\mathrm{m}}
\end{gathered}
$$

where $X_{\mathrm{m}}$ is the ratio of the total diffraction intensity of the major crystal planes in both tetragonal and monoclinic phases with volume fraction $V_{t}$ and $V_{\mathrm{m}}$, respectively, $I_{\mathrm{m}}$ is a preferential plane of the monoclinic phase, $I_{\mathrm{t}}$ is a preferential plane of the tetragonal phase. The transformation of tetragonal to monoclinic in zirconia is a reversible thermal martensitic transformation involving a significant temperature hysteresis $\left(\sim 20{ }^{\circ} \mathrm{C}\right)$, volume alteration (4-5\%), and considerable shear strain (14-15\%) [62].

(a)

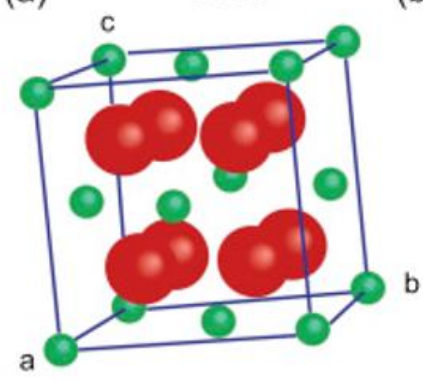

(b) $\mathrm{c}$

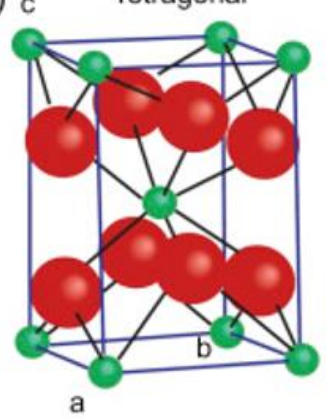

(c)



Figure 5. (a-c) Crystal structures and crystallographic information for monoclinic, tetragonal, and cubic phases in $\mathrm{ZrO}_{2}$, respectively [63] (reproduced with permission number: 5055990208243, Elsevier).

Yan and Han reported a decreasing tendency to form $\mathrm{m}-\mathrm{ZrO}_{2}$ in the PEO coating with increasing the applied voltage [42]. The immediate temperature of the PEO discharge region varies between $10^{3}$ and $10^{6}{ }^{\circ} \mathrm{C}$ during film formation. The transformation of $\mathrm{m}$ $\mathrm{ZrO}_{2}$ to $\mathrm{c}-\mathrm{ZrO}_{2}$ enhances once a high-temperature pulse is created with increasing the applied voltages [42]. Sandhyarani and his coworkers conducted the PEO coating in tri-sodium orthophosphate (TSOP) electrolyte for 2, 4, 6, and $8 \mathrm{~min}$. They did not find separate phosphate phases in their characterizations, implying that the $\mathrm{ZrO}_{2}$ film was doped with phosphorous (P). They also deduced that two factors influencing the phase transformation between monoclinic and tetragonal. The volume threshold of $7 \%$ was found for the tetragonal phase. Increasing the treatment time did not cause increased volume percentage of the tetragonal phase, and even the oxide film was produced at higher applied voltage. They inferred that the crystal size acted as an opposite factor for the higher localized temperature. Transformation above the threshold was restricted because crystals sintered to produce larger crystallites at higher temperatures induced a transformation from tetragonal to monoclinic with greater stability [13,64]. Authors reported that the PEO coatings produced in TSOP electrolyte with different treatment times demonstrated a smooth surface with very fine morphology, which was not similar to what was observed from other electrolytes [42]. They reported that discharge channels emerged on the whole surface in the form of circular spots spread out uniformly. Prolonging the PEO process caused a reduction of the population of discharge channels and enlargement of the discharge channel diameter, which could be ascribed to creating amplified sparks within the treatment time [13]. It is worth mentioning that prolonging the PEO treatment can result in stronger discharges amplified enough to sinter more elements grabbed from the electrolyte in the coating [7]. 
In another study, Yan et al. reported the formation of a porous surface with an average pore size of $3 \mu \mathrm{m}$, where the average pore size increased three times to offer greater feasibility for accumulation of hydroxyapatite compounds [47]. The PEO coating was composed of a major phase of $\mathrm{m}-\mathrm{ZrO}_{2}$ and a trace of $t-\mathrm{ZrO}_{2}$, where a homogenous distribution of pores was found over the coating. The cross-section showed a continuous bilayer film, where the compact inner layer was $2 \mu \mathrm{m}$ in thickness [47]. Simka et al. produced PEO coatings using different $\mathrm{K}_{2} \mathrm{SiO}_{3}$ concentrations of $0.1,0.5$, and $1 \mathrm{~mol} / \mathrm{dm}^{3}$ at a constant voltage of $400 \mathrm{~V}$. They showed that the PEO coating produced at lower silicate concentration contained plenty of small pores with diameters less than $1 \mu \mathrm{m}$. The crosssection revealed that the coating was not uniform and that the outer layer of the coating separated in several regions [43]. Authors could show that the PEO coating was formed mainly at the metal-film interface owing to the inward migration of oxygen ions. Thus, the effect of the cation transport was not significant in the film growth. Moreover, silicon species could be traced at a relatively high concentration in the outer layer of the film with a thickness of approximately $20 \mathrm{~nm}$. The formation of this exterior layer may be related to the outward transfer of $\mathrm{Zr}^{4+}$ ions, probably facilitated by the silica precipitation because of the reduction of the $\mathrm{pH}$ adjacent to the coating surface. The authors concluded that silicon could participate in the coating composition remarkably upon applying a potential above the breakdown voltage of the oxide layer. They also showed that silicon present in the coating in the form of silica and silicates.

Yan et al. produced $\mathrm{Al}_{2} \mathrm{O}_{3} / \mathrm{ZrO}_{2}$ composite coatings using the PEO process in the electrolyte containing $\mathrm{NaAlO}_{2}$ with different concentrations to systematically investigate the microstructure, bond strength, and microhardness of coatings [48]. The authors observed that increasing the concentration of $\mathrm{NaAlO}_{2}$ changed the conductivity, which indirectly affected the anodization regime. At the fixed voltage, increasing conductivity was accompanied by the greater anodization current. Therefore, a more intensive plasma discharge would be created on the surface, where extremely intensive discharges were seen at $0.35 \mathrm{M}$ $\mathrm{NaAlO}_{2}$ inducing forming larger discharge pores. The morphology of the PEO coating formed at $0.2 \mathrm{M} \mathrm{NaAlO}_{2}$ consisted of numerous nonuniformly distributed grains with different sizes and several cracks between accumulated grains. However, the needle-like crystals $\left(\alpha-\mathrm{Al}_{2} \mathrm{O}_{3}\right)$ emerged on the coating surface with increasing $\mathrm{NaAlO}_{2}$ concentration. For this case, the coatings consisted of three layers: the outer layer, with the largest quantity of $\mathrm{Al}$; the intermediate layer and the inner layer, where the gradian of $\mathrm{Al}$ content gradually shifted to zero at the coating/substrate interface [48]. The coating was dominantly composed of $\alpha-\mathrm{Al}_{2} \mathrm{O}_{3}, t-\mathrm{ZrO}_{2}$, and $\mathrm{m}-\mathrm{ZrO}_{2}$ phases. Finally, the authors understood that more $\alpha-\mathrm{Al}_{2} \mathrm{O}_{3}$ and $t-\mathrm{ZrO}_{2}$ phases developed in the coating composition with increasing $\mathrm{NaAlO}_{2}$ concentration within a certain range.

Cengiz and Gencer reported the formation of PEO coatings on $\mathrm{Zr}$ samples in sodium silicate containing electrolyte and a coating process with different treatment times, as shown in Figure 6. First, the surface of the PEO coating produced in 5 min was evaluated. It was found that the surface was relatively smooth and contained the pancake-like features distributed irregularly with central micropores in the range of $1 \mu \mathrm{m}$. As displayed in Figure $6 \mathrm{~b}-\mathrm{f}$, prolonging the treatment time decreased the number of micropores on the surface. At the same time, the pancake-like features rose significantly in their size to approximately $25 \mu \mathrm{m}$. As shown in Figure $6 \mathrm{e}, \mathrm{f}$, for the PEO coating produced above $20 \mathrm{~min}$, the pancake-like features disappeared completely. A smooth surface appeared with a continuation of the coating process [45]. It was evident that, with the progression of the PEO process, a larger content of aggregated materials could accumulate adjacent to the opening of the pores and form irregular semispherical shapes with random distribution, as shown clearly in Figure 6d. Although most of the accumulated aggregates were dense, their structures were porous and distributed irregularly on the surface. It was found that increasing the number of microcracks and the appearance of flaking features on the surface resulted from the continuation of the PEO process for above $90 \mathrm{~min}$ [45]. It was also noticed that the surface roughness was impacted greatly by the treatment time, with roughness 
shifted from 0.63 to $8.3 \mu \mathrm{m}$ as treatment time increased from 5 to $120 \mathrm{~min}$. This tendency was also confirmed for the coating thickness, which rose linearly from 4.1 to $167 \mu \mathrm{m}$ [45].
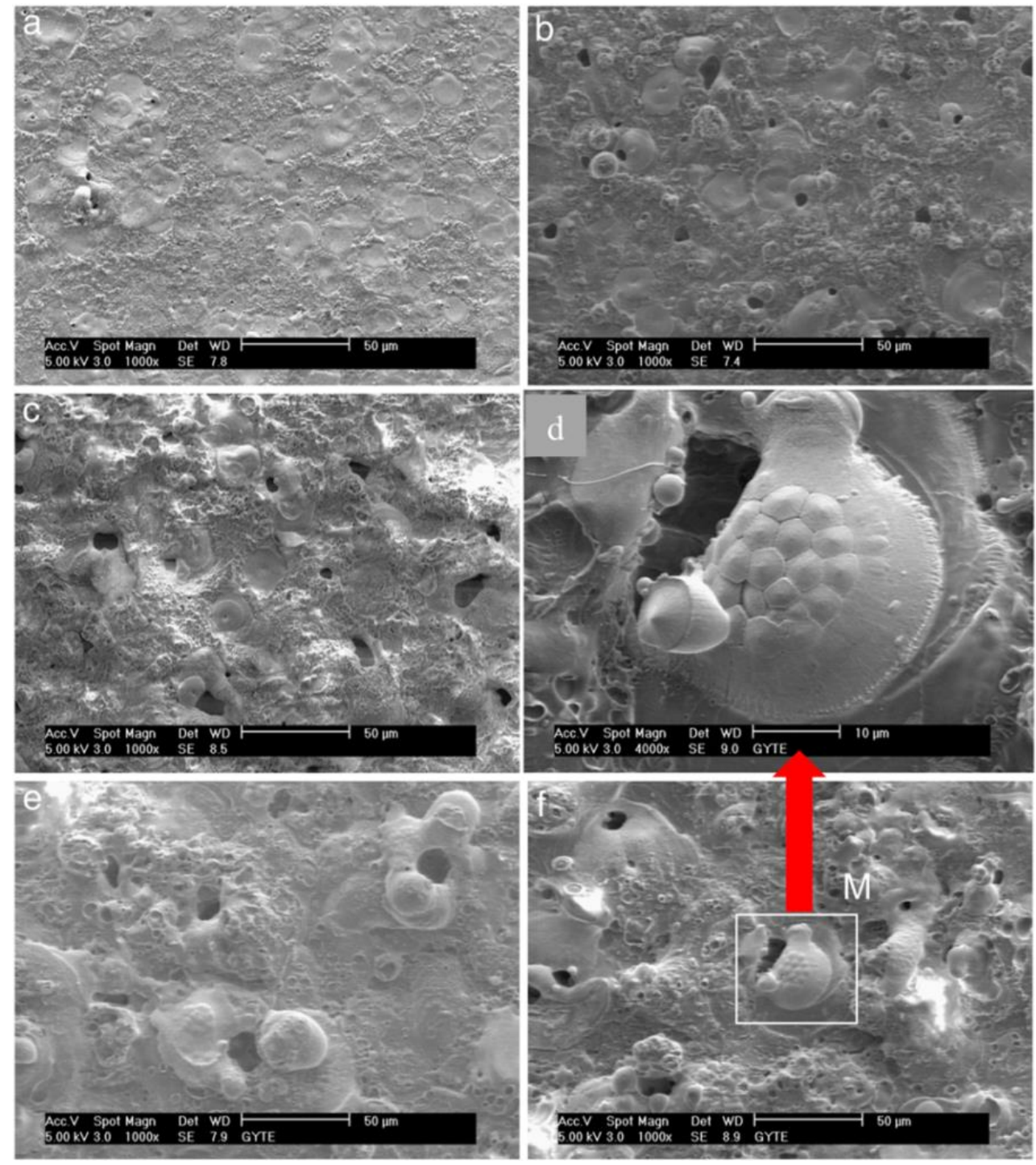

Figure 6. SEM images from the surface morphology of the PEO coating on pure $\mathrm{Zr}$ for the period of (a) 5, (b) 10, (c) 20, (d) 60, (e) 30, (f) $60 \mathrm{~min}$. (d) High magnification of a typical SEM image of the cluster in equiaxed condition captured from the sub-figure (f) and marked as " $\mathrm{M}$ " for the processing time of $60 \mathrm{~min}$ [45] (reproduced with permission number: 5043520384143, Elsevier).

Another important remark was the composition of $\mathrm{PEO}$ coatings, where both $\mathrm{m}-\mathrm{ZrO}_{2}$ and $t-\mathrm{ZrO}_{2}$ phases started to form from the beginning of the PEO coating process, and the dominant phase was monoclinic. In striking contrast, the authors found out that the phase content of the PEO coating formed in the silicate electrolyte was not significantly influenced by the coating thickness. Thus, they did not report any tendency in phase transformation resulting from the thickening of the coating, despite the results of other studies. In fact, the $\mathrm{m}-\mathrm{ZrO}_{2} / t-\mathrm{ZrO}_{2}$ ratio remained constant during the PEO process. In contrast, due to a stabilizing effect of the silicate electrolyte, it was also reported that the $t-\mathrm{ZrO}_{2} / \mathrm{m}-\mathrm{ZrO} \mathrm{r}_{2}$ ratio was higher in the outer layer compared to that in the inner layer of the coating [20]. This striking inconsistency can be ascribed to the presence of alloying elements.

Matykina et al. investigated the microstructure, morphology of the PEO coating on $\mathrm{Zirlo}^{\mathrm{TM}}$, a Zr alloy produced for nuclear applications [19]. They could show a three-layered 
coating produced for $30 \mathrm{~min}$ using the final voltage of $150 \mathrm{~V}$. In fact, the PEO coating consisted of a thin, compact barrier layer formed anodically, an intermediate layer, and an outer layer rich in silicon. Authors found all three zirconia phases were present in the coating composition, where $\mathrm{Si}$ was also present in the top porous layer in the form of the amorphous compound. Moreover, they found the thickness of the outer layer did not change significantly with treatment time in the soft sparking region, where the elemental ratio of $\mathrm{Si} / \mathrm{Zr}$ in the outer layer after the appearance of a soft sparking regime during the prolonged treatment was 10 times higher than that of the anodic film formed before the commencement of sparking [19].

In a comparative study on the role of electrolytes on the coating composition by Cheng et al., it was shown that the silicate electrolyte promoted the greater thickness of coating comprising outer layers enriched in silicon and inner layers consisting of $\mathrm{m}-\mathrm{ZrO}_{2}$ and $t-\mathrm{ZrO}_{2}$ [20]. A remarkable feature on the coating surface produced in the silicate electrolyte at the early stages of striking microdischarges was forming the pancake-like features, implying extrusion of melted coating materials from discharge channels. However, the microstructure of the PEO coating formed during the steady-state process was an equiaxed dendritic center, in which the peripheral cellular orientation may be noticeable. In striking contrast, the PEO coating formed in the pyrophosphate electrolyte was much thinner and contained numerous cracks. The coating was only composed of $\mathrm{m}-\mathrm{ZrO}_{2}$, and the layered structure was not detected, unlike the coating formed in silicate electrolyte. The addition of silicate to the pyrophosphate electrolyte could improve the coating morphology by decreasing the number of cracks and boosting the proportionality of the tetragonal phase in the composition compared to the monoclinic phase. The flawed morphology observed for the coating formed in the pyrophosphate electrolyte could be attributed to the high stress created by the phase transformation from tetragonal to monoclinic. It was evident incorporating the silicon species from the electrolyte could partially stabilize the tetragonal phase. Cheng et al. studied the influence of different AC current frequencies on the morphology of the PEO coating in the silicate solution [28]. They reported the appearance of large pores spotted at the pancake-like features for the PEO coating produced at $100 \mathrm{~Hz}$ for 5 min on Zircaloy-4, indicating that the schematic model shown in Figure $3 \mathrm{c}$ was valid here and that sparks of type D had struck the surface. A fine dendritic structure was also observed in the outer region for the prolonged processing time.

After this, the authors pursued the PEO process by investigating the influence of sparking regimes on the phase composition and morphology of the coating produced on Zircaloy-2 [25]. They found the pancake-like feature prevailed the surface morphology of the PEO coating produced after $1 \mathrm{~min}$. These features were formed because of type $\mathrm{B}$ discharges, illustrated schematically in Figure $3 \mathrm{~b}$. As mentioned, type B discharges were the strongest discharges during the $\mathrm{PEO}$ process originating from near the substrate/coating interface. Increasing treatment time caused enlarging dimensions of the pancake-like structures due to being struck by stronger discharges. Moreover, the detection of some pores on the dense outer layer surface and the porous inner layer could be ascribed to creating type D and type E discharges, as shown in the schematic model in Figure 3b. Moreover, the PEO coating composition altered with the silicate concentration in the electrolyte. The $\mathrm{m}-\mathrm{ZrO}_{2}$ dominated the coating in dilute silicate electrolyte, and $t-\mathrm{ZrO}_{2}$ content increased at higher silicate concentration.

The microstructure of the PEO coating identifies with many factors, including the types and concentrations of electrolytes, the substrate composition and the electrical parameters. The surface morphology and cross-section images of the coating formed in silicate and aluminate electrolytes for $30 \mathrm{~min}$ are shown in Figure $7 \mathrm{a}-\mathrm{h}$, respectively. The surfaces in both coatings revealed pores, cracks, and pancake-like features, while the surface of the coating formed in aluminate was less rough than that formed in silicate. The typical features of solidification structures and spallation regions of the coatings were the two distinctive indicators of PEO coatings formed in silicate and aluminate electrolytes, as shown in Figure $7 \mathrm{c}, \mathrm{g}$, respectively [26]. Although the structure shown in Figure $7 \mathrm{c}$ was relatively rare, 
its creation required the presence of long-lasting molten materials due to prolonged sparks. The cross-sections illustrated in Figure 7d comprised a three-layer structure, including an inner barrier layer with a thickness of $\sim 1 \mu \mathrm{m}$ affixed on the alloy surface, an intermediate layer that was porous and cracked significantly, and an outer layer with extensive cracks. Figure 7f,g illustrated regions related to the coating's surface where part of the coating was separated due to spallation. The cross-section in Figure 7h displayed the morphology of the coating formed in aluminate electrolyte for $30 \mathrm{~min}$ and partially impacted by spallation. Later, Cheng et al. reported the formation of a bilayer PEO oxide in electrolytes containing $\mathrm{NaAlO}_{2}$ and $\mathrm{KOH}$ for $30 \mathrm{~min}$ treatment [27]. It was also noted that coatings formed in aluminate electrolytes for shorter times resembled features similar to those shown in Figure 7e, such as pores, cracks, and pancake-like features. However, the spalled regions were absent. They found a noticeable connection between creating "soft sparking" and the inner layer growth. Dendritic growth of the tetragonal $\mathrm{ZrO}_{2}$ phase throughout the outer layer was apparent, similar to other studies [20,25,26,28,65]. The thickness of the inner layer before and after the occurrence of "soft sparking" showed significant growth and thickening during this short period. The growth of the inner layer during the "soft sparking" period mainly filled the gap between the bilayer PEO coating [27]. Authors found that pancake-like features disappeared for the PEO coating formed in concentrated $\mathrm{NaAlO}_{2}$ electrolyte, suggesting decreasing intensity and population density of sparks as the most effective factors [25,27]. Unlike the study by Yan et al. [48], the PEO coating obtained by Cheng et al. in a less concentrated electrolyte did not contain needle-like crystals of $\alpha-\mathrm{Al}_{2} \mathrm{O}_{3}$. The coating was only composed of tetragonal and monoclinic zirconia phases, in which the tetragonal phase was found in greater quantity in the outer layer for the coating formed in aluminate electrolyte [26].

Sandhyarani et al. studied the role of electrolyte composition on the structure and morphology of the PEO coating. They used 5 different mixtures of $\mathrm{Na}_{2} \mathrm{SiO}_{3}, \mathrm{Na}_{3} \mathrm{PO}_{4}$, and $\mathrm{KOH}$ to find a suitable electrolyte system with optimum properties for biocompatibility applications [36]. It was evident that the relative proportion of tetragonal to monoclinic phases altered concerning electrolytes. Again, reducing the monoclinic phase in electrolytes containing silicate confirmed that Si stabilized the tetragonal phase at low temperatures. Sandhyarani and his coworker found that increasing silicate ion concentration caused alteration of preferential orientation from $(\overline{111})$ to (200) in the monoclinic phase, in which the oxide film formed in a higher concentration of $\mathrm{Na}_{2} \mathrm{SiO}_{3}$ was grown fully in (200) orientation [36]. This was inconsistent with other studies, in which the growth of $\mathrm{m}-\mathrm{ZrO}_{2}$ film in (200) orientation was not reported for the PEO coating on $\mathrm{Zr}$ and its alloys in silicate electrolyte $[19,25-27,43,45,49,65,66]$. After considering studies on the PEO coating in silicate electrolyte, authors concluded that the alteration of orientation in oxide films was probably due to the duty cycle effect, in which switching from low duty cycles (26-30\%) to high duty cycles (95\%) significantly shifted the oxide film growth in (200) orientation. These phenomena could be explained by considering the role of high duty cycles on inducing a higher localized heat with the PEO treatment time and increasing the surface mobility of molten oxide that all eventually ended up changing to surface rearrangement of growing crystalline zirconia [36]. The addition of $\mathrm{KOH}$ to electrolyte modified the surface morphology significantly. The porosity and roughness of the oxide films decreased, and the coating became more uniform. Furthermore, PEO coating formed in silicate electrolyte demonstrated greater wettability and surface energy.

Zhang et al. produced $\mathrm{Al}_{2} \mathrm{O}_{3}-\mathrm{ZrO}_{2}$ composite coatings at $400 \mathrm{~V}$ for treatment time from 5 to $30 \mathrm{~min}$ [29]. The PEO coating formed at prolonged treatment time contained the highest quantity of crystalline nanoplate-like alumina, distributed uniformly, interweaved with each other, and placed vertically over the surface [29]. It was remarkable that Zhang and his coworkers found the ratio of $t-\mathrm{ZrO}_{2} / \mathrm{m}-\mathrm{ZrO}_{2}$ rose from depth to surface of the PEO coating formed in aluminate electrolyte. 

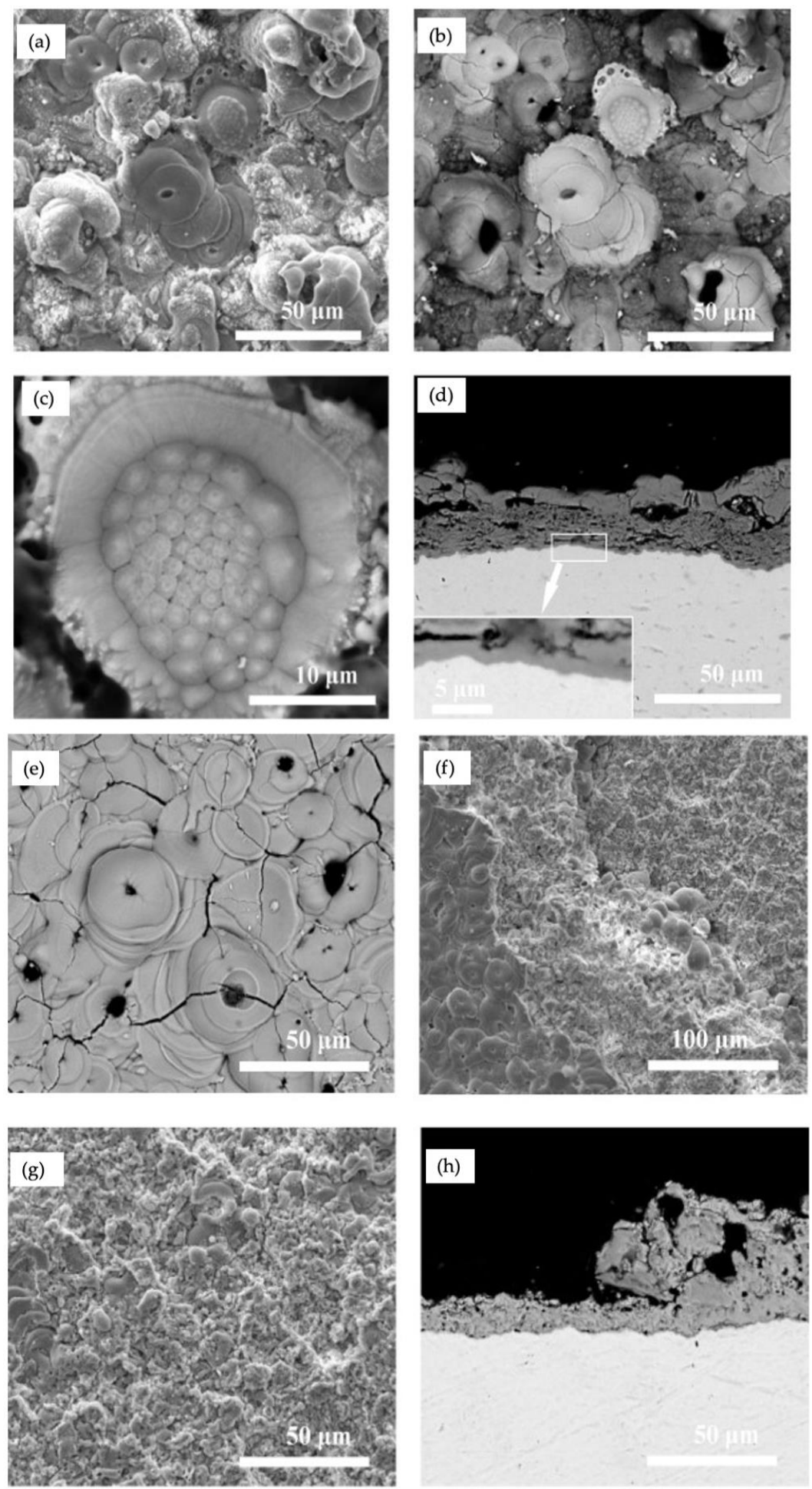

Figure 7. (a-c) Surface morphology, and (d) Cross-sectional image of the PEO coating formed for $1800 \mathrm{~s}$ in the silicate electrolyte; (e-g) Surface morphology, and (h) Cross-sectional image of a coating formed for $1800 \mathrm{~s}$ in the aluminate electrolyte [26] (reproduced with permission number: 5043480179625, Elsevier).

The effect of anion deposition in different concentrations of aluminate electrolyte was studied by Cheng et al. [41]. The surface morphology of coatings was examined for the entire various concentration of aluminates used in electrolytes. First, in dilute electrolyte with $2 \mathrm{~g} / \mathrm{L} \mathrm{NaAlO}_{2}$, the pancake-like features were reported for both unipolar and bipolar 
conditions, in which each pancake contained a pinhole at the center due to the outlet of gases accumulated under the pancake-like features created by the strong discharges (type E) [10,38]. Figure 8 illustrates cross-sectional images of all $\mathrm{PEO}$ coatings formed at $\mathrm{NaAlO}_{2}$ concentrations of $2,16,32$, and $56 \mathrm{~g} / \mathrm{L}$. The coating thickness formed during the bipolar regime was very thin $(\sim 10 \mu \mathrm{m})$ and exhibited a single-layer nature in the cross-section shown in Figure 8a. However, the coating formed under a unipolar regime was a bi-layered structure with a thickness of $\sim 30 \mu \mathrm{m}$. Remarkably, large lateral pores trans passing the compact outer layer and the thin inner layer were apparent for the coating formed in an electrolyte containing $2 \mathrm{~g} / \mathrm{L} \mathrm{NaAlO}_{2}$, as shown in Figure 8b. The cross-sectional images for coating formed in $16 \mathrm{~g} / \mathrm{L} \mathrm{NaAlO}_{2}$ under unipolar and bipolar regimes were different, as shown in Figure $8 \mathrm{c}, \mathrm{d}$. The unipolar structure resembled the structure formed in a dilute electrolyte, in which internal pores were detected. In contrast, the intervals between outer and inner layers in the bipolar coating were filled with dark coating materials instead of being void, as shown in the central part of Figure 8d. EDS analysis for areas shown in figures is shown in Figure 8. The ratio of $\mathrm{Al} / \mathrm{Zr}$ highlighted the fact that the concentration of aluminate in electrolytes greatly influenced the proportion of anions incorporating into the coating. For coatings formed in an electrolyte containing $32 \mathrm{~g} / \mathrm{L} \mathrm{NaAlO}_{2}$, the cross-section image of the coating formed under a unipolar regime illustrated the presence of big pores and generated interruption in the continuity of the coating, similar to coatings formed in dilute electrolytes. In striking contrast, the surface morphology of bipolar coating did not show pancake-like structures. At the same time, some white patches appeared on the surface of the bipolar coating. The coating growth behavior altered significantly for the PEO process is highly concentrated aluminate electrolyte $\left(56 \mathrm{~g} / \mathrm{L} \mathrm{NaAlO}_{2}\right)$, in which the entire surface covered with patches of white materials deposited at a high rate. A prolonged process at highly concentrated electrolyte caused alteration of the morphology distinguishably. The pancake-like features disappeared from the coating surface. The surface of coatings contained noodle-like features. The surface morphology was extremely nonuniform for the unipolar regime, while mound-like features were created by a "sintering arc" being completely visible. The thickening of the coating under the unipolar regime, shown in cross-sectional images in Figure 8g, represented an extraordinary behavior due to protruding mound-like features. Moreover, the appearance of long cracks at the coating-substrate interface indicated the weak adherence of the coating. In contrast, the coating formed under the bipolar regime was more uniform. With no mound-like features appearing, the cross-section of coating indicated greater uniformity, and interfacial cracks did not progress [33].

Studying the mechanism of the PEO coating in different electrolyte concentrations taught us that pancake features were created on the surface during the process in low and moderate electrolyte concentrations under unipolar regimes. Pancake-like features were mainly created by discharge types B or E due to a dielectric breakdown process. Gas evolution accompanying the strong discharges generated large internal pores [38]. Figure $8 \mathrm{j}$ shows a suggested model by Cheng et al. for explaining the formation mechanism of pancake-like features and big pores [33]. Visually, each discharge spark was encapsulated by a non-luminous gas bubble [67]. It could be envisioned that negatively charged ions from electrolyte situated on the bubble surface and electron emissions from the electrolyte into the gas bubble stimulated discharges; however, electrons could be positioned at the oxide-electrolyte interface unrelated to the gas bubble [68]. To model the PEO process in highly concentrated electrolytes, the schematic presentation shown in Figure 8i could be suggested for the growth of the coating under a unipolar regime. The shown "soft sparking" was generated by heavy anion deposition and the accumulation of new compounds on the surface. The sintering arcs could generate the fast precipitations of alumina. Weak sparks were responsible for creating the conventional anodic film, making flower-like features on the surface. 

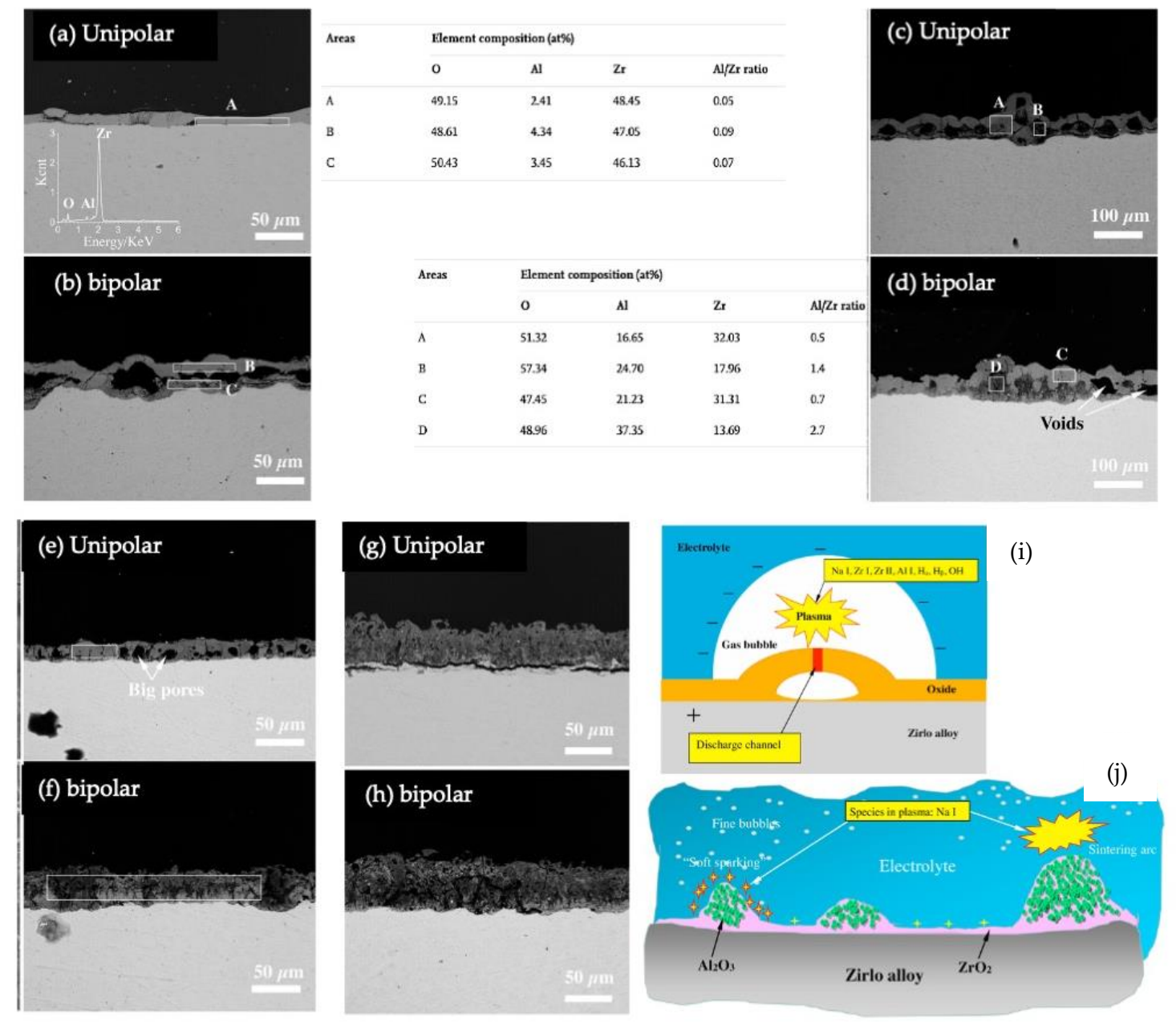

Figure 8. The cross-sectional images of the coatings under unipolar and bipolar regimes in electrolyte containing: $(\mathbf{a}, \mathbf{b}) 2 \mathrm{~g} / \mathrm{L}$

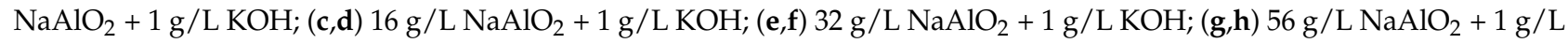
$\mathrm{KOH}$; (i) Schematic illustration of the growth steps through discharge penetration; (j) Schematic illustration of the coating formation process in highly concentrated electrolyte and under unipolar regime [33] (reproduced with permission number: 5043511188587, Elsevier).

Arun et al. used a single-step PEO procedure accompanied by electrophoretic deposition (EPD) to produce a composite coating in phosphate electrolyte by incorporating nanoparticles, including $\mathrm{Al}_{2} \mathrm{O}_{3}, \mathrm{CeO}_{2}$, and $\mathrm{ZrO}_{2}$, separately [55]. They studied microstructural alteration and found that the surface morphology was modified significantly after the involvement of nanoparticles. The participation of $\mathrm{Al}_{2} \mathrm{O}_{3}$ and $\mathrm{CeO}_{2}$ nanoparticles promoted phase transformation from monoclinic to tetragonal in $\mathrm{ZrO}_{2}$. At the same time, the surface nature turned to hydrophobic with the incorporation of particles due to less porous morphology. Another study also reported the incorporation of $\mathrm{SiC}$ into $\mathrm{ZrO}_{2}$ composite coating using the EPD method in aluminate, phosphate, and silicate electrolytes. Monoclinic zirconia was the dominant phase in phosphate and silicate electrolytes, while tetragonal zirconia was dominant in aluminate electrolytes [69].

\section{Concluding Remarks and Future Outlook}

The ceramic oxide base coating can be synthesized on $\mathrm{Zr}$ and its alloys successfully using the PEO process in different alkaline and acidic electrolytes with outstanding coating adherence to the substrate. The wavy feature of the metal/coating interface could induce greater coating adherence to the substrate. The PEO coating depending on process parameters, could result in various surface morphologies, including various populations of pores and cracks, different surface roughness, different coating composition and features. 
Generally, the thickness of the oxide film rose with the treatment time, consequently approaching the breakdown voltage. After this, there were three regions of discharge regimes, including dynamic discharges, near steady-state, and steady-state. Indeed, the number of discharges and discharge channels reduced with thickening the PEO coating. The discharge regimes could be categorized based on the electrolyte concentration, in which strong plasma discharges were dominant at dilute or moderately concentrated electrolyte, while the dominant discharges in concentrated electrolyte were sporadic patches of weak discharges or some localized "sintering arc".

Thus, discharge channels enlarged in size because stronger sparks struck the surface. This, in turn, led to increasing the content of debris materials thrown out from plasma channels and accumulated surrounding plasma channels. The ejaculation of materials through plasma channels was stimulated by high pressure that was created by evaporated materials. Hence, at stronger sparks' locations, more materials were ejaculated and splashed out of the plasma channels forming spots that look like geothermal boiling mud pools.

Using the silicate electrolyte for the PEO process promotes greater sintering of the outer layer through more significant participation of elements driven from the electrolyte and reducing the melting temperature of $\mathrm{ZrO}_{2}$. The PEO coating formed on $\mathrm{Zr}$ alloys in the silicate electrolyte consisted of a three-layered coating, including a thin barrier layer, a porous inner layer, and a relatively compact outer layer. Both tetragonal and monoclinic phases were present in the inner and outer layers. An enriched silicon layer could be seen on the surface of the coating. However, plenty of cracks were found on the coating formed in the pyrophosphate, which can be attributed to phase transformation from tetragonal to monoclinic zirconia. The different morphologies of the coatings could be related to the differing natures of the microdischarges and participation of silicon species in the coatings. Different distribution of $t-\mathrm{ZrO}_{2}$ and $\mathrm{m}-\mathrm{ZrO}_{2}$ between the outer layer and the inner layer of the PEO coating could be related to the different thermal conditions in the upper and lower coating regions.

The presence of silicon species in electrolytes has demonstrated its effectiveness in stabilizing the tetragonal phase, where the proportion of $t-\mathrm{ZrO}_{2}$ in the coating composition intensified with increased concentration of the silicate in the electrolyte. For instance, in one case, $t-\mathrm{ZrO}_{2}$ content rose from $\sim 8$ to $27 \mathrm{wt} \%$ by increasing the concentration of $\mathrm{Na}_{2} \mathrm{SiO}_{3} \cdot 9 \mathrm{H}_{2} \mathrm{O}$ from 8 to $30 \mathrm{~g} / \mathrm{L}$. However, the PEO coating in the phosphate-based electrolyte was dominantly composed of $\mathrm{m}-\mathrm{ZrO}_{2}$. PEO coatings grew at higher rates in concentrated aluminate electrolytes, while the intensity and population of discharges noticeably decreased. In concentrated electrolytes, pancake-like features disappeared, tetragonal zirconia became the dominant phase, and $\gamma-\mathrm{Al}_{2} \mathrm{O}_{3}$ started growing at the prolonged PEO procedures. Pancake-like features were created on the surface of PEO coating due to penetration of strong discharges generated either in dilute electrolytes for both bipolar and unipolar regimes or in moderately concentrated electrolytes for only unipolar regimes. In concentrated electrolytes, the dominant coating formation mechanism was the anion deposition, which changed the nature of PEO discharges.

The main intent of this review is to trigger inspiration for new research that will develop and expand the science and technique of the PEO coating fabrication with improved features and broader applications. To help provide such inspiration and provoke new research perspectives for future research in this exciting field, selective ideas for new research are presented in the following paragraphs. Despite the considerable research performed over the past three decades, there have been no definitive experiments that discernibly shed light on the mechanism of phase transformation from cubic to tetragonal and then to monoclinic. Many efforts have been devoted to identifying optimum process parameters to increase the proportionality of the tetragonal phase over the monoclinic phase. However, the role of each parameter, such as the composition of the electrolyte, electrical processing parameters, has not been comprehensively discovered. Clarification of the effect of quenching rate from tetragonal phase to monoclinic phase demands systematic experiments. Therefore, more work aimed at understanding the martensitic transition from 
tetragonal to monoclinic is warranted. We recommend experiments to be performed in the following areas:

Advanced surface characterization: The nature of oxide film in the form of layers stacking over the substrate and different ratios of tetragonal phase to monoclinic phase in different layers need to be addressed. Why does the tetragonal phase form in lower proportionality in the inner layer compared to the outer layer? Are strong discharges the only factor in forming a greater quantity of monoclinic phase in the inner layer?

In situ analysis: What is the temperature of the plasma region at the substrate-coating interface, where the inner layer forms? In situ analysis is complicated by the evolution of gases at the origination of discharges.

What is the optimum ratio of tetragonal to monoclinic phase to obtain the best performance in various applications? How can the aging effect be retarded to prevent the transition of tetragonal to monoclinic during prolonged use?

What is the role of post-treatments in modifying the surface features of PEO coatings? Heat treatment and laser treatment of surface and controlling the rate of quenching from higher temperature to room temperature are facile procedures to change the ratio of tetragonal to monoclinic phase. The ratio of tetragonal to monoclinic phases can be shifted to the same ratio for different stacking layers of the PEO coating. This modification can prevent the accumulation of mismatching stress between layers and prevent lateral detachment of layers.

Author Contributions: C.V.R. conceived and supervised this work. N.A. collected all the data, obtained permission to use the data existing in the literature, and compiled the scientific validations. Both authors involved in preparing the manuscript. Finally, All authors have read and agreed to the published version of the manuscript.

Funding: The authors also acknowledge, with pleasure, support from the National Science Foundation (NSF) with NSF-PREM grant \#DMR-1827745.

Acknowledgments: N.A. acknowledges with pleasure the technical support and encouragement provided by the Center for Advanced Materials Research (CMR), UTEP. N.A. also acknowledges the Research Associate opportunity provided by CMR, UTEP.

Conflicts of Interest: The authors declare no conflict of interest.

\section{References}

1. Yau, T.-L.; Sutherlin, R.C.; Chang, A.W. Corrosion of Zirconium and Zirconium Alloy. In Corrosion: Materials; Stephen, D.C., Bernard, S.C., Eds.; ASM International: Ohio, OH, USA, 2018; Chapter 20; pp. 300-324.

2. Yau, T.-L.; Annamalai, V.E. Corrosion of Zirconium and Its Alloys; Elsevier: Amsterdam, The Netherlands, 2016; ISBN 978-0-12-803581-8.

3. Banerjee, S.; Banerjee, M. Nuclear applications: Zirconium alloys. Ref. Modul. Mater. Sci. Mater. Eng. 2016. [CrossRef]

4. Xiao, B.; Sun, J.; Ruzsinszky, A.; Feng, J.; Haunschild, R.; Scuseria, G.E.; Perdew, J.P. Testing density functionals for structural phase transitions of solids under pressure: $\mathrm{Si}, \mathrm{SiO}_{2}$, and Zr. Phys. Rev. B 2013, 88, 184103. [CrossRef]

5. Uchida, M.; Kim, H.-M.; Kokubo, T.; Tanaka, K.; Nakamura, T. Structural dependence of apatite formation on zirconia gels in a simulated body fluid. J. Ceram. Soc. Jpn. 2002, 110, 710-715. [CrossRef]

6. Wang, G.; Liu, X.; Ding, C. Phase composition and in-vitro bioactivity of plasma sprayed calcia stabilized zirconia coatings. Surf. Coat. Technol. 2008, 202, 5824-5831. [CrossRef]

7. Sreekanth, D.; Rameshbabu, N.; Venkateswarlu, K. Effect of various additives on morphology and corrosion behavior of ceramic coatings developed on AZ31 magnesium alloy by plasma electrolytic oxidation. Ceram. Int. 2012, 38, 4607-4615. [CrossRef]

8. Pauporté, T.; Finne, J.; Kahn-Harari, A.; Lincot, D. Growth by plasma electrolysis of zirconium oxide films in the micrometer range. Surf. Coat. Technol. 2005, 199, 213-219. [CrossRef]

9. Mohedano, M.; Lu, X.; Matykina, E.; Blawert, C.; Arrabal, R.; Zheludkevich, M.L. Plasma Electrolytic Oxidation (PEO) of Metals and Alloys; Wandelt, K.B.T.-E., Ed.; Elsevier: Oxford, UK, 2018; pp. 423-438. ISBN 978-0-12-809894-3.

10. Kaseem, M.; Fatimah, S.; Nashrah, N.; Ko, Y.G. Recent progress in surface modification of metals coated by plasma electrolytic oxidation: Principle, structure, and performance. Prog. Mater. Sci. 2021, 117, 100735. [CrossRef]

11. Ikonopisov, S.; Girginov, A.; Machkova, M. Electrical breaking down of barrier anodic films during their formation. Electrochim. Acta 1979, 24, 451-456. [CrossRef]

12. Santos, J.S.; Lemos, S.G.; Goncalves, W.N.; Bruno, O.M.; Pereira, E. Characterization of electrical discharges during spark anodization of zirconium in different electrolytes. Electrochim. Acta 2014, 130, 477-487. [CrossRef] 
13. Sandhyarani, M.; Rameshbabu, N.; Venkateswarlu, K.; Sreekanth, D.; Subrahmanyam, C. Surface morphology, corrosion resistance and in vitro bioactivity of $\mathrm{P}$ containing $\mathrm{ZrO}_{2}$ films formed on $\mathrm{Zr}$ by plasma electrolytic oxidation. J. Alloys Compd. 2013, 553, 324-332. [CrossRef]

14. Ikonopisov, S. Theory of electrical breakdown during formation of barrier anodic films. Electrochim. Acta 1977, 22, 1077-1082. [CrossRef]

15. Venkateswarlu, K.; Rameshbabu, N.; Sreekanth, D.; Bose, A.C.; Muthupandi, V.; Babu, N.K.; Subramanian, S. Role of electrolyte additives on in-vitro electrochemical behavior of micro arc oxidized titania films on Cp Ti. Appl. Surf. Sci. 2012, 258, 6853-6863. [CrossRef]

16. Yerokhin, A.; Snizhko, L.; Gurevina, N.; Leyland, A.; Pilkington, A.; Matthews, A. Spatial characteristics of discharge phenomena in plasma electrolytic oxidation of aluminium alloy. Surf. Coat. Technol. 2004, 177-178, 779-783. [CrossRef]

17. Arrabal, R.; Matykina, E.; Hashimoto, T.; Skeldon, P.; Thompson, G. Characterization of AC PEO coatings on magnesium alloys Surf. Coat. Technol. 2009, 203, 2207-2220. [CrossRef]

18. Jaspard-Mécuson, F.; Czerwiec, T.; Henrion, G.; Belmonte, T.; Dujardin, L.; Viola, A.; Beauvir, J. Tailored aluminium oxide layers by bipolar current adjustment in the Plasma Electrolytic Oxidation (PEO) process. Surf. Coat. Technol. 2007, 201, 8677-8682. [CrossRef]

19. Matykina, E.; Arrabal, R.; Skeldon, P.; Thompson, G.; Wang, P.; Wood, P. Plasma electrolytic oxidation of a zirconium alloy under AC conditions. Surf. Coat. Technol. 2010, 204, 2142-2151. [CrossRef]

20. Cheng, Y.; Matykina, E.; Skeldon, P.; Thompson, G. Characterization of plasma electrolytic oxidation coatings on Zircaloy-4 formed in different electrolytes with AC current regime. Electrochim. Acta 2011, 56, 8467-8476. [CrossRef]

21. Hussein, R.O.; Nie, X.; Northwood, D.O.; Yerokhin, A.; Matthews, A. Spectroscopic study of electrolytic plasma and discharging behaviour during the plasma electrolytic oxidation (PEO) process. J. Phys. D Appl. Phys. 2010, 43, 43. [CrossRef]

22. Hussein, R.; Nie, X.; Northwood, D. An investigation of ceramic coating growth mechanisms in plasma electrolytic oxidation (PEO) processing. Electrochim. Acta 2013, 112, 111-119. [CrossRef]

23. Hussein, R.O.; Northwood, D.O.; Nie, X. Processing-microstructure relationships in the plasma electrolytic oxidation (PEO) coating of a magnesium alloy. Mater. Sci. Appl. 2014, 5, 124-139. [CrossRef]

24. Cheng, Y.-L.; Xue, Z.-G.; Wang, Q.; Wu, X.-Q.; Matykina, E.; Skeldon, P.; Thompson, G. New findings on properties of plasma electrolytic oxidation coatings from study of an Al-Cu-Li alloy. Electrochim. Acta 2013, 107, 358-378. [CrossRef]

25. Cheng, Y.; Wu, F.; Matykina, E.; Skeldon, P.; Thompson, G. The influences of microdischarge types and silicate on the morphologies and phase compositions of plasma electrolytic oxidation coatings on Zircaloy-2. Corros. Sci. 2012, 59, 307-315. [CrossRef]

26. Cheng, Y.; Wu, F.; Dong, J.; Wu, X.; Xue, Z.; Matykina, E.; Skeldon, P.; Thompson, G. Comparison of plasma electrolytic oxidation of zirconium alloy in silicate- and aluminate-based electrolytes and wear properties of the resulting coatings. Electrochim. Acta 2012, 85, 25-32. [CrossRef]

27. Cheng, Y.; Cao, J.; Peng, Z.; Wang, Q.; Matykina, E.; Skeldon, P.; Thompson, G. Wear-resistant coatings formed on Zircaloy-2 by plasma electrolytic oxidation in sodium aluminate electrolytes. Electrochim. Acta 2014, 116, 453-466. [CrossRef]

28. Cheng, Y.; Matykina, E.; Arrabal, R.; Skeldon, P.; Thompson, G. Plasma electrolytic oxidation and corrosion protection of Zircaloy-4. Surf. Coat. Technol. 2012, 206, 3230-3239. [CrossRef]

29. Zhang, L.; Zhang, W.; Han, Y.; Tang, W. A nanoplate-like $\alpha-\mathrm{Al}_{2} \mathrm{O}_{3}$ out-layered $\mathrm{Al}_{2} \mathrm{O}_{3}-\mathrm{ZrO}_{2}$ coating fabricated by micro-arc oxidation for hip joint prosthesis. Appl. Surf. Sci. 2016, 361, 141-149. [CrossRef]

30. Martini, C.; Ceschini, L.; Tarterini, F.; Paillard, J.; Curran, J. PEO layers obtained from mixed aluminate-phosphate baths on Ti-6Al-4V: Dry sliding behaviour and influence of a PTFE topcoat. Wear 2010, 269, 747-756. [CrossRef]

31. Yan, Y.; Han, Y.; Huang, J. Formation of $\mathrm{Al}_{2} \mathrm{O}_{3}-\mathrm{ZrO}_{2}$ composite coating on zirconium by micro-arc oxidation. Scr. Mater. 2008, 59, 203-206. [CrossRef]

32. Yerokhin, A.; Leyland, A.; Matthews, A. Kinetic aspects of aluminium titanate layer formation on titanium alloys by plasma electrolytic oxidation. Appl. Surf. Sci. 2002, 200, 172-184. [CrossRef]

33. Cheng, Y.; Wang, T.; Li, S.; Cheng, Y.; Cao, J.; Xie, H. The effects of anion deposition and negative pulse on the behaviours of plasma electrolytic oxidation (PEO) - A systematic study of the PEO of a Zirlo alloy in aluminate electrolytes. Electrochim. Acta 2017, 225, 47-68. [CrossRef]

34. Wang, C.; Wang, F.; Han, Y. Structural characteristics and outward-inward growth behavior of tantalum oxide coatings on tantalum by micro-arc oxidation. Surf. Coat. Technol. 2013, 214, 110-116. [CrossRef]

35. Li, J.; Cai, H.; Xue, X.; Jiang, B. The outward-inward growth behavior of microarc oxidation coatings in phosphate and silicate solution. Mater. Lett. 2010, 64, 2102-2104. [CrossRef]

36. Sandhyarani, M.; Prasadrao, T.; Rameshbabu, N. Role of electrolyte composition on structural, morphological and in-vitro biological properties of plasma electrolytic oxidation films formed on zirconium. Appl. Surf. Sci. 2014, 317, 198-209. [CrossRef]

37. Lu, S.-F.; Lou, B.-S.; Yang, Y.-C.; Wu, P.-S.; Chung, R.-J.; Lee, J.-W. Effects of duty cycle and electrolyte concentration on the microstructure and biocompatibility of plasma electrolytic oxidation treatment on zirconium metal. Thin Solid Films 2015, 596, 87-93. [CrossRef]

38. Cheng, Y.; Cao, J.; Mao, M.; Xie, H.; Skeldon, P. Key factors determining the development of two morphologies of plasma electrolytic coatings on an Al-Cu-Li alloy in aluminate electrolytes. Surf. Coat. Technol. 2016, 291, 239-249. [CrossRef] 
39. Mécuson, F.; Czerwiec, T.; Belmonte, T.; Dujardin, L.; Viola, A.; Henrion, G. Diagnostics of an electrolytic microarc process for aluminium alloy oxidation. Surf. Coat. Technol. 2005, 200, 804-808. [CrossRef]

40. Matykina, E.; Arrabal, R.; Scurr, D.; Baron, A.; Skeldon, P.; Thompson, G. Investigation of the mechanism of plasma electrolytic oxidation of aluminium using $18 \mathrm{O}$ tracer. Corros. Sci. 2010, 52, 1070-1076. [CrossRef]

41. Cheng, Y.-L.; Cao, J.-H.; Mao, M.-K.; Peng, Z.-M.; Skeldon, M.-K.M.P.; Thompson, G. High growth rate, wear resistant coatings on an Al-Cu-Li alloy by plasma electrolytic oxidation in concentrated aluminate electrolytes. Surf. Coat. Technol. 2015, $269,74-82$. [CrossRef]

42. Yan, Y.; Han, Y. Structure and bioactivity of micro-arc oxidized zirconia films. Surf. Coat. Technol. 2007, 201, 5692-5695. [CrossRef]

43. Simka, W.; Sowa, M.; Socha, R.P.; Maciej, A.; Michalska, J. Anodic oxidation of zirconium in silicate solutions. Electrochim. Acta 2013, 104, 518-525. [CrossRef]

44. Lan, R.; Dong, L.; Wang, C.; Liang, T.; Tian, J. Influence of oxidation time on microstructure and composition of micro-arc oxidation coatings formed on zirconium. Mater. Res. Innov. 2014, 18, S2-123-S2-127. [CrossRef]

45. Cengiz, S.; Gencer, Y. The characterization of the oxide based coating synthesized on pure zirconium by plasma electrolytic oxidation. Surf. Coat. Technol. 2014, 242, 132-140. [CrossRef]

46. Dunleavy, C.; Golosnoy, I.; Curran, J.; Clyne, T. Characterisation of discharge events during plasma electrolytic oxidation. Surf. Coat. Technol. 2009, 203, 3410-3419. [CrossRef]

47. Han, Y.; Yan, Y.; Lu, C. Ultraviolet-enhanced bioactivity of $\mathrm{ZrO}_{2}$ films prepared by micro-arc oxidation. Thin Solid Films 2009, 517, 1577-1581. [CrossRef]

48. Yan, Y.; Han, Y.; Li, D.; Huang, J.; Lian, Q. Effect of $\mathrm{NaAlO}_{2}$ concentrations on microstructure and corrosion resistance of $\mathrm{Al}_{2} \mathrm{O}_{3} / \mathrm{ZrO}_{2}$ coatings formed on zirconium by micro-arc oxidation. Appl. Surf. Sci. 2010, 256, 6359-6366. [CrossRef]

49. Zou, Z.; Xue, W.; Jia, X.; Du, J.; Wang, R.; Weng, L. Effect of voltage on properties of microarc oxidation films prepared in phosphate electrolyte on $\mathrm{Zr}-1 \mathrm{Nb}$ alloy. Surf. Coat. Technol. 2013, 222, 62-67. [CrossRef]

50. Cheng, Y.; Peng, Z.; Wu, X.; Cao, J.; Skeldon, P.; Thompson, G. A comparison of plasma electrolytic oxidation of Ti-6Al-4V and Zircaloy-2 alloys in a silicate-hexametaphosphate electrolyte. Electrochim. Acta 2015, 165, 301-313. [CrossRef]

51. Stojadinović, S.; Vasilić, R.; Radić, N.; Grbić, B. Zirconia films formed by plasma electrolytic oxidation: Photoluminescent and photocatalytic properties. Opt. Mater. 2015, 40, 20-25. [CrossRef]

52. Cengiz, S.; Uzunoglu, A.; Stanciu, L.; Tarakci, M.; Gencer, Y. Direct fabrication of crystalline hydroxyapatite coating on zirconium by single-step plasma electrolytic oxidation process. Surf. Coat. Technol. 2016, 301, 74-79. [CrossRef]

53. Fidan, S.; Muhaffel, F.; Riool, M.; Cempura, G.; De Boer, L.; Zaat, S.; Czyrska-Filemonowicz, C.; Cimenoglu, H. Fabrication of oxide layer on zirconium by micro-arc oxidation: Structural and antimicrobial characteristics. Mater. Sci. Eng. C 2017, 71, 565-569. [CrossRef]

54. Aktuğ, S.L.; Durdu, S.; Yalçın, E.; Çavuşoğlu, K.; Usta, M. In vitro properties of bioceramic coatings produced on zirconium by plasma electrolytic oxidation. Surf. Coat. Technol. 2017, 324, 129-139. [CrossRef]

55. Arun, S.; Arunnellaiappan, T.; Rameshbabu, N. Fabrication of the nanoparticle incorporated PEO coating on commercially pure zirconium and its corrosion resistance. Surf. Coat. Technol. 2016, 305, 264-273. [CrossRef]

56. Cengiz, S.; Azakli, Y.; Tarakci, M.; Stanciu, L.; Gencer, Y. Microarc oxidation discharge types and bio properties of the coating synthesized on zirconium. Mater. Sci. Eng. C 2017, 77, 374-383. [CrossRef] [PubMed]

57. Sandhyarani, M.; Rameshbabu, N.; Venkateswarlu, K.; Rama Krishna, L. Fabrication, characterization and in-vitro evaluation of nanostructured zirconia/hydroxyapatite composite film on zirconium. Surf. Coat. Technol. 2014, 238, 58-67. [CrossRef]

58. Wang, Y.; Feng, W.; Xing, Y.; Ge, Y.; Guo, L.; Ouyang, J.; Jia, D.; Zhou, Y. Degradation and structure evolution in corrosive LiOH solution of microarc oxidation coated Zircaloy-4 alloy in silicate and phosphate electrolytes. Appl. Surf. Sci. 2018, 431, 2-12. [CrossRef]

59. Aktug, S.L.; Durdu, S.; Aktas, S.; Yalcin, E.; Usta, M. Characterization and investigation of in vitro properties of antibacterial copper deposited on bioactive $\mathrm{ZrO}_{2}$ coatings on zirconium. Thin Solid Films 2019, 681, 69-77. [CrossRef]

60. Li, Z.-Y.; Cai, Z.-B.; Cui, X.-J.; Liu, R.-R.; Yang, Z.-B.; Zhu, M.-H. Influence of nanoparticle additions on structure and fretting corrosion behavior of micro-arc oxidation coatings on zirconium alloy. Surf. Coat. Technol. 2021, 410, 126949. [CrossRef]

61. Ma, W.; Wen, L.; Guan, R.; Sun, X.; Li, X. Sintering densification, microstructure and transformation behavior of $\mathrm{Al}_{2} \mathrm{O}_{3} / \mathrm{ZrO}_{2}\left(\mathrm{Y}_{2} \mathrm{O}_{3}\right)$ composites. Mater. Sci. Eng. A 2008, 477, 100-106. [CrossRef]

62. Basu, B.; Balani, K. Toughness optimization in zirconia-based ceramics. In Advanced Structural Ceramics; John Wiley \& Sons: Hoboken, NJ, USA, 2011; pp. 173-214.

63. Farid, S.B. Structure, microstructure, and properties of bioceramics. In Bioceramics: For Materials Science and Engineering; Elsevier BV: Amsterdam, The Netherlands, 2019; pp. 39-76.

64. Mercera, P.D.L.; Van Ommen, J.G.; Doesburg, E.B.M.; Burggraaf, A.J.; Ross, J.R.H. Zirconia as a support for catalysts: Evolution of the texture and structure on calcination in air. Appl. Catal. 1990, 57, 127-148. [CrossRef]

65. Cheng, Y.-L.; Wu, F. Plasma electrolytic oxidation of zircaloy-4 alloy with DC regime and properties of coatings. Trans. Nonferrous Met. Soc. China 2012, 22, 1638-1646. [CrossRef]

66. Chen, Y.; Nie, X.; Northwood, D. Investigation of Plasma Electrolytic Oxidation (PEO) coatings on a Zr-2.5Nb alloy using high temperature/pressure autoclave and tribological tests. Surf. Coat. Technol. 2010, 205, 1774-1782. [CrossRef] 
67. Troughton, S.C.; Nomine, A.; Henrion, G.; Clyne, T.W. Synchronised electrical monitoring and high speed video of bubble growth associated with individual discharges during plasma electrolytic oxidation. Appl. Surf. Sci. 2015, 359, 405-411. [CrossRef]

68. Wang, L.; Chen, L.; Yan, Z.; Fu, W. Optical emission spectroscopy studies of discharge mechanism and plasma characteristics during plasma electrolytic oxidation of magnesium in different electrolytes. Surf. Coat. Technol. 2010, 205, 1651-1658. [CrossRef]

69. Sukumaran, A.; Sampatirao, H.; Balasubramanian, R.; Parfenov, E.; Mukaeva, V.; Nagumothu, R. Formation of $\mathrm{ZrO}_{2}-\mathrm{SiC}$ composite coating on zirconium by plasma electrolytic oxidation in different electrolyte systems comprising of $\mathrm{SiC}$ nanoparticles. Trans. Indian Inst. Met. 2018, 71, 1699-1713. [CrossRef] 